\title{
WestVirginiaUniversity
}

THE RESEARCH REPOSITORY @ WVU

Graduate Theses, Dissertations, and Problem Reports

2006

\section{Thermal conductivity characterization of composite materials}

\author{
Bhyrav Mutnuri \\ West Virginia University
}

Follow this and additional works at: https://researchrepository.wvu.edu/etd

\section{Recommended Citation}

Mutnuri, Bhyrav, "Thermal conductivity characterization of composite materials" (2006). Graduate Theses, Dissertations, and Problem Reports. 1715.

https://researchrepository.wvu.edu/etd/1715

This Thesis is protected by copyright and/or related rights. It has been brought to you by the The Research Repository @ WVU with permission from the rights-holder(s). You are free to use this Thesis in any way that is permitted by the copyright and related rights legislation that applies to your use. For other uses you must obtain permission from the rights-holder(s) directly, unless additional rights are indicated by a Creative Commons license in the record and/ or on the work itself. This Thesis has been accepted for inclusion in WVU Graduate Theses, Dissertations, and Problem Reports collection by an authorized administrator of The Research Repository @ WVU. For more information, please contact researchrepository@mail.wvu.edu. 


\section{Thermal Conductivity Characterization of Composite Materials}

\section{Bhyrav Mutnuri}

Thesis Submitted to the

College of Engineering and Mineral Resources

at West Virginia University

in partial fulfillment of the requirements

for the degree of

\section{Master of Science \\ in \\ Mechanical Engineering}

Dr. Kenneth Means, Ph.D., Chair

Dr. Gangarao Hota, Ph.D.

Dr. Eric Johnson, Ph.D.

Dr. Ruifeng Liang, Ph.D.

\section{Department of Mechanical Engineering \\ Morgantown, West Virginia \\ 2006}

Keywords: Thermal conductivity, Three Dimensional Thermal Conductivity, Composite materials, E-glass, Carbon Fibers, Additives 


\section{ABSTRACT \\ Thermal Conductivity Characterization of Composite Materials}

\section{Bhyrav Mutnuri}

Thermal conductivity of a polymer composite is a function of resin type, fiber type and architecture, fiber volume fraction, direction of heat flow, and service temperature. Recognizing the thermal responses in Fiber Reinforced Polymer (FRP) composite decks play a critical role in their performance, accurate thermal measurements of FRP decks are essential.

The objective of the research is to attain better understanding of global and local thermal behavior of a composite structural system through fundamental understanding of thermal conductivity properties. The literature reveals that a major focus has been placed on measurements of thermal conductivity in through-the-thickness direction of a FRP composite. Therefore, current research focus has been on characterization of thermal conductivity in the planar direction (along the direction of fiber and transverse direction of fiber) of a composite laminate. The characterization has been carried out using 'Guarded heat flow meter method' in accordance with ASTM E 1530. The results obtained from this study are useful for the prediction of thermal conductivity of E-glass and Carbon fiber composites with vinyl ester.

Results showed that E-glass/Vinyl ester samples exhibited in-plane and through-thethickness thermal conductivity of $0.35 \pm 0.05 \mathrm{~W} / \mathrm{m} \mathrm{K}$. Thermal conductivity of Carbon/Vinyl ester composite is almost twice the conductivity in transverse and four times greater than through-the-thickness direction. Addition of $10 \mathrm{wt} \%, 12.5 \mathrm{wt} \%$ of graphite powder additive in neat vinyl ester resin increased the conductivity by nearly $88 \%, 170 \%$ respectively. The experimental values from this research correlated well with results from rule of mixtures in inplane direction and also correlated with other theoretical methods. The results of this research would also be useful for in situ non-destructive testing of composite structures using Infrared thermography. 


\section{ACKNOWLEDGEMENTS}

First I would like to thank god for giving me this wonderful opportunity to enhance my knowledge and thinking ability through pursing this masters degree. I wish to express my sincere gratitude to Dr. Liang and Dr. Hota for introducing me to the field of research and guiding me through out this work. I would like to thank Dr. Means for serving as committee chair and for his support during this work and I extend my thanks to Dr. Johnson for his valuable advises as a committee member.

I wish to thank Jim Hall, Dave Turner, Paul Porter, Jerry Nestor and Bill Comstock for their help in preparing samples. I wish to thank Linda Rogers, Lynne Jacobs, Debbie Willis and the staff of CFC for their support during the course of work.

I thank Federal Highway Administration / Department of Transportation for funding this project, Bedford Reinforced Plastics, Inc. for donating FRP bridge deck samples and Anter Corporation, Pittsburgh, $\mathrm{Pa}$ for providing latest model instrument for testing the samples for thermal conductivity.

I wish to express my appreciation to Suneetha Burla for her help during experimental work and thesis write-up. I would like to extend my thanks to Amarnath, Deepika for helping me in preparing carbon fiber composite blocks and Sandilya Hota for his support as an officemate during this study.

Last but not the least, I am very much thankful to my mom, family, relatives and friends for their loving support and encouragement which made all this possible. 


\section{TABLE OF CONTENTS}

ABSTRACT - -

ACKNOWLEDGEMENTS --

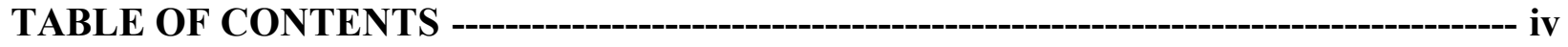

LIST OF FIGURES--- vi

LIST OF TABLES -

CHAPTER 1 --_---- 1

INTRODUCTION

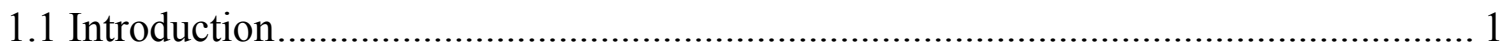

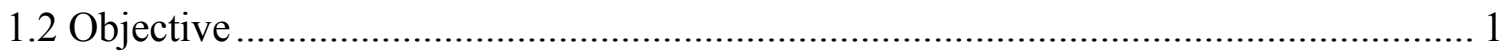

1.3 Scope

CHAPTER 2 --_-_- 4

LITERATURE REVIEW ...........................................................4

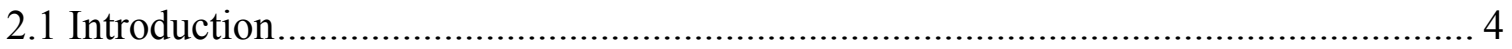

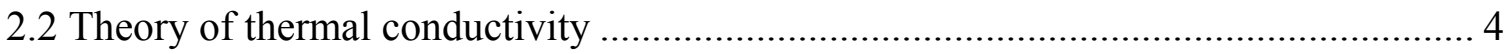

2.3 Factors affecting thermal conductivity of composite materials ................................... 5

2.4 Experimental approach for thermal conductivity measurements............................... 10

2.5 Theoretical approach for thermal conductivity predictions ....................................... 14

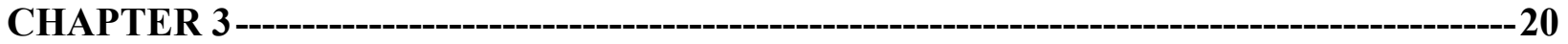

TESTING METHODS......................................................................20

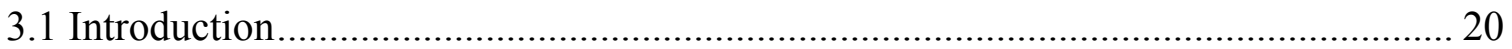

3.2 Experimental setup...................................................................................... 20

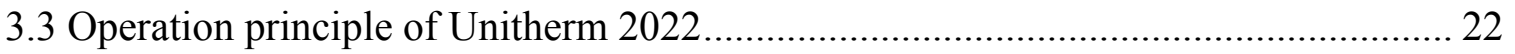

3.4 Sample requirement and test procedure .............................................................. 23

3.5 Determination of fiber volume fraction .............................................................. 24

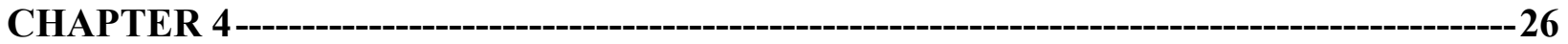

MATERIALS AND SAMPLE PREPARATION ...............................26

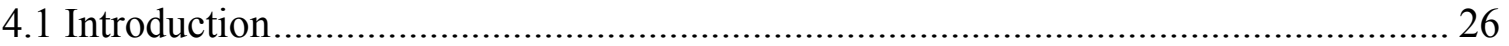

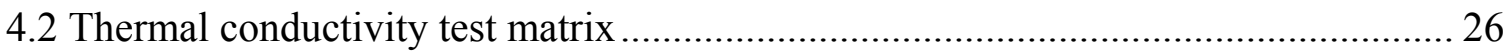

4.3 Resin casting with or without additives ................................................................. 28 
4.4 E-glass/vinyl ester laminates with or without stitching ..................................... 31

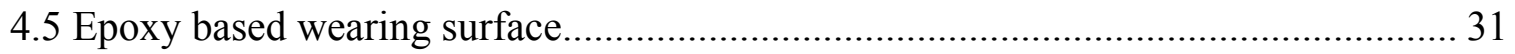

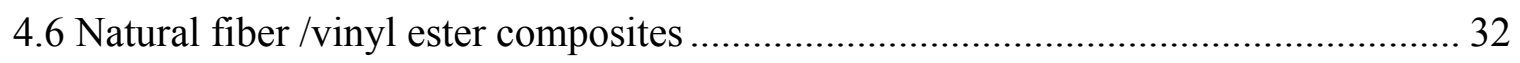

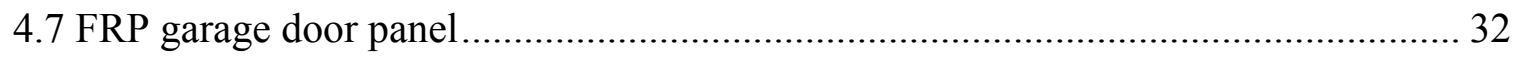

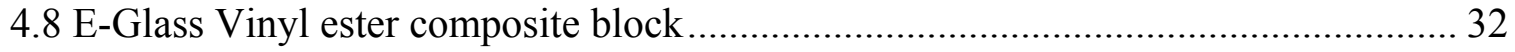

4.9 Carbon fiber/ vinyl ester composite sheet and block .......................................... 33

4.10 Prodeck 4 and Prodeck 8 bridge decks ............................................................. 34

CHAPTER 5-------------------------------------------------------------------------------------------------37

EXPERIMENTAL RESULTS AND DISCUSSION ........................37

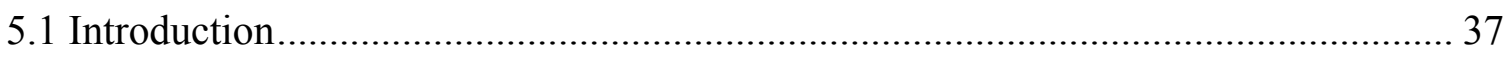

5.2 Neat resin castings and resin castings with additives ...................................... 37

5.3 E-glass /vinyl ester laminates with or without stitching ..................................... 42

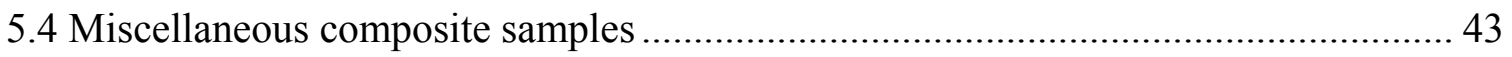

5.7 E-glass/vinyl ester composite block............................................................. 45

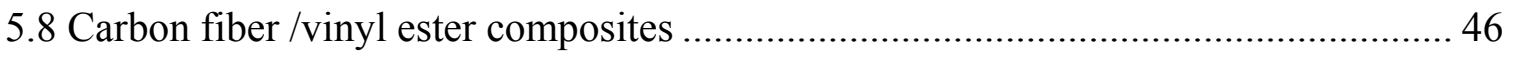

5.9 Prodeck 4 and Prodeck 8 bridge deck samples .................................................. 49

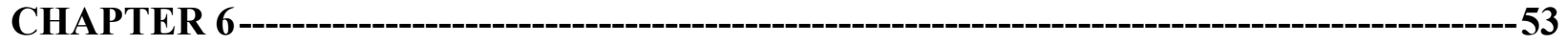

VALIDATION OF MODEL PREDICTIONS ............................53

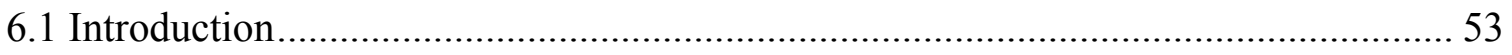

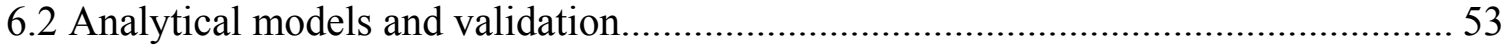

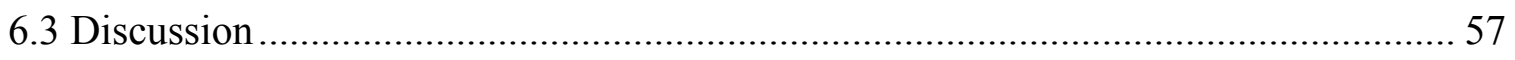

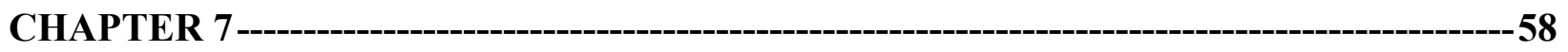

CONCLUSIONS AND RECOMMENDATIONS ..............................58

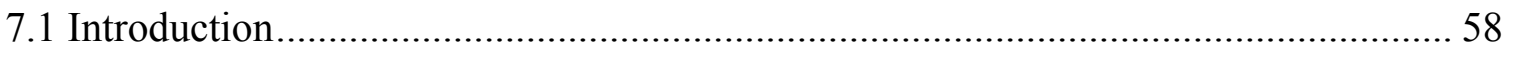

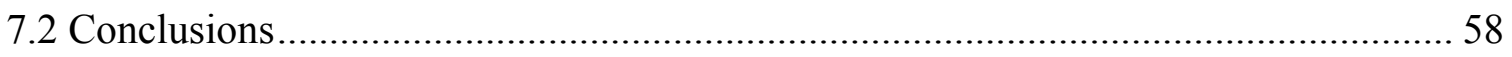

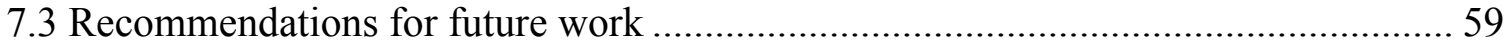

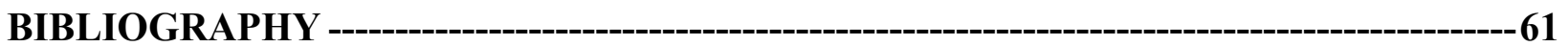




\section{LIST OF FIGURES}

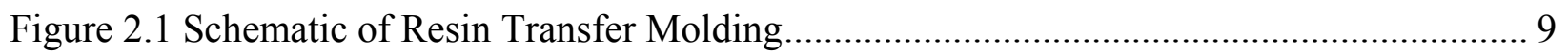

Figure 2.2 Schematic of Pultrusion Process ................................................................... 10

Figure 2.3 Schematic representation of transient pulse method ................................................. 12

Figure 2.4 Schematic representation of Laser Pulse Operator.................................................... 13

Figure 3.1 Experimental set up of Unitherm 2022 ............................................................. 20

Figure 3.2 Schematic model showing the system arrangement in Unitherm 2022 ..................... 21

Figure 3.3 SEM pictures showing the number of layers and their alignment............................... 25

Figure 4.1 Samples of Epoxy, Vinyl ester and Polyester resins on top row; samples with different particulate sizes of graphite powder additive, chopped carbon fiber additives in bottom two rows

Figure 4.2 Samples of Derakane 8084 vinyl ester resin with or without additives ..................... 30

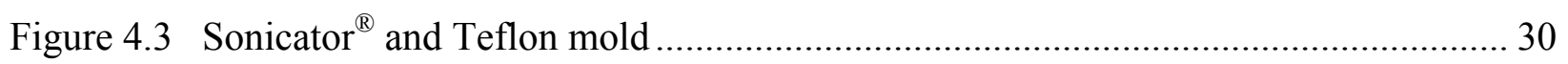

Figure 4.4 Miscellaneous FRP composite samples tested ......................................................... 31

Figure 4.5 Samples of bridge deck, natural fiber, deck with epoxy wearing surface................... 32

Figure 4.6 E-glass/vinyl ester block and three dimensional samples, carbon tow and carbon/vinyl

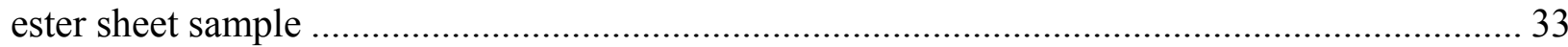

Figure 4.7 Carbon fiber /vinyl ester composite block and specimens along fiber direction (marked $\mathrm{X}$ ), in transverse direction $(\mathrm{Y})$ and through the thickness direction $(\mathrm{Z})$.......................... 34 Figure 4.8 Samples prepared from web and flange sections of Prodeck 4 …….......................... 36 Figure 4.9 Samples prepared from web and flange sections of Prodeck 8 …………................. 36 Figure 5.2 Thermal conductivity variations with graphite additives, with carbon nano-tubes in

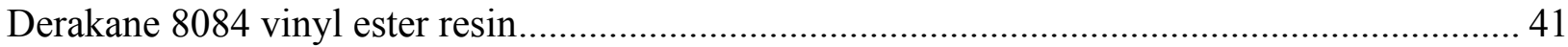

Figure 5.3 Thermal conductivity variations with change in particulate size of............................ 41

graphite additives in Hetron 922 vinyl ester resin .................................................................... 41

Figure 5.4 Thermal conductivity variations with chopped carbon fiber additives in Hetron $922 \mathrm{~L}$

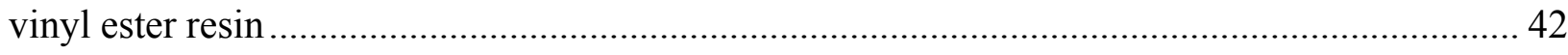

Figure 5.5 Thermal conductivity variations for Carbon/Vinyl ester composites.......................... 49 


\section{LIST OF TABLES}

Table 4.1 Thermal Conductivity Test Matrix ....................................................................... 27

Table 5.1 Thermal conductivity values of different resins ................................................ 38

Table 5.2 Thermal conductivity values of vinyl ester resins with different additives and

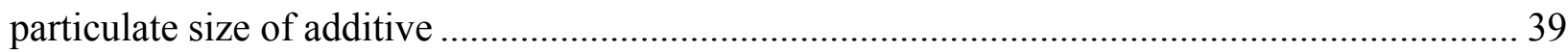

Table 5.3 Thermal conductivity of E-glass /vinyl ester laminates........................................ 43

Table 5.4 Thermal conductivity of miscellaneous composites .............................................. 44

Table 5.5 Thermal conductivities of E-glass/vinyl ester composite block samples .................. 46

Table 5.6 Thermal conductivities of carbon fiber/vinyl ester composite blocks I, II................ 48

Table 5.7 Thermal conductivity of FRP bridge deck samples in three directions ..................... 50

Table 5.8 Thermal conductivity values of 4 -inch deck web section samples............................ 51

Table 5.9 Thermal conductivity values of 4 -inch deck flange section samples ....................... 51

Table 5.10 Thermal conductivity values of 8 -inch deck web section samples......................... 52

Table 5.11 Thermal conductivity values of 8 -inch deck flange section samples ..................... 52

Table 6.1 Theoretical models for transverse effective thermal conductivity............................. 54

Table 6.2 Parameters of the samples verified using theoretical methods ................................ 55

Table 6.3 Comparison of experimental and theoretical values in (through the thickness effective thermal conductivity) for E glass/Vinyl ester sample and Carbon/Vinyl ester samples............. 56 


\section{CHAPTER 1}

\section{INTRODUCTION}

\subsection{Introduction}

Composites are engineered materials made out of two or more components. Most of the composites can be tailored to obtain properties better than individual constituents. A polymer composite reinforced with fiber is called FRP composite. Considering a composite, which involves two or more macro constituent phases, the matrix is referred to as continuous phase and the fibers are called the reinforcing phase (Mirmira, 1999). The fibers increase the strength and stiffness, increase thermal and fatigue properties, provide better dimensional stability and electrical resistivity. Whereas the primary function of the resin is to transfer load, to hold the fibers, protect fibers from environment and mechanical abrasion. Matrix also carries transverse loads and interlaminar shear stresses (Barbero, 1998). The advantages of composites include high strength to weight ratio, non-corrosiveness, less maintenance, high electrical resistance,

wear resistance, electromagnetic transparency, appeasing appearance etc. Composites can be manufactured in different ways depending upon matrix, reinforcement and application. Different manufacturing methods include Hand-lay up, Compression molding, Resin Transfer Molding (RTM), Pultrusion, Autoclave and Filament molding etc.

Considering the mechanical and thermal properties of composites, they are anisotropic in nature (i.e. the properties vary with orientation), but most of the composites can be considered as orthotropic (i.e. nine different constants are required to describe an orthotropic material). This behavior of the material also causes the development of large values of thermal stresses due to temperature gradient across the section. This problem emphasizes the necessity of knowledge on thermal behavior of composites.

\subsection{Objective}

The long-term vision of this research is to develop composites with reduced thermal stresses to avoid catastrophic failures and to develop FRP composite bridges with self-deicing capacity creating environmental friendly atmosphere. To achieve these goals, research was required in the fields of thermal expansion, thermal conductive behavior and design of composite structure. Knowledge about the thermal conductivity can be utilized in finding the optimum heat source required to conduct Infrared testing (non-destructive) on composite components in service 
as well as in designing of composite materials with reduced thermal stresses. The objective of this present work is to understand the thermal behavior of FRP composites by developing a database of thermal conductivity for different FRP composite materials. Different composite samples are to be distinguished based upon the following parameters:

- Different resin

- Different fibers

- Effect of heat flow direction

- Fiber volume fraction

- Effect of additive materials and particle size of additive

- Different manufacturing methods

\subsection{Scope}

The structure of this report is as follows. Chapter 2 contains a brief description of published literature on prediction and determination of thermal conductivity of composite materials. Most of the literature deals with analytical determination of thermal conductivity, with few published papers dealing with the experimental methods determining thermal conductivity of composite materials. Those papers on experimental methods mainly focused on thermal conductivity of FRP materials in a single direction.

Chapter 3 deals with test method to determine thermal conductivity. The measurements of thermal conductivity of composite materials were carried out on a guarded heat flow meter entitled Anter system model Unitherm 2022. This model is fully computerized and equipped with a mid range flux module covering the thermal conductivity of materials in the range of 0.1 to $40 \mathrm{~W} / \mathrm{m}-\mathrm{K}$ in terms of test standard ASTM E 1530.

Chapter 4 presents details on constituent materials and manufacturing techniques of test samples. Fiber reinforcements include E-Glass, Carbon fiber, and natural fiber, while resin types range from vinyl ester, polyester, and epoxy. Most samples were manufactured in CFC-WVU laboratories using conventional manufacturing techniques like Hand-lay up, Compression molding, Resin Transfer Molding. However, two types of bridge decks i.e. Prodeck 4 and Prodeck 8 were manufactured through pultrusion process by Bedford Reinforced Plastics Inc. Bedford, PA, and were supplied to CFC-WVU for experimental evaluation.

Chapter 5 presents thermal conductivity values obtained for a variety of composite materials. This chapter also includes discussions on the influence of various parameters on the 
thermal conductivity of FRP composites. Chapter 6 compares experimental thermal conductivity values to values computed from available empirical models. Chapter 7 gives a summary and directions for future work. 


\section{CHAPTER 2}

\section{LITERATURE REVIEW}

\subsection{Introduction}

Increasing use of composites for various applications emphasizes its importance/significance in the thermal property analysis of an engineering system. Thermal conductivity of a composite (combination of two or more constituents) can be measured by experimental methods. Analytical equations are essential to predict thermal conductivities of a composite material. Information on the thermal properties of composite materials would facilitate the design of an engineering system made of FRPs.

Published literature is rich with investigations of mechanical properties of composites (Gowayed, 1995). Fewer publications focused on thermal properties. Several publications like Hashin (1979), Caruso et al (1986), Muralidhar (1989), Springer and Tsai (1967) addressing different theoretical approaches for predicting thermal conductivity of composite materials have been noted. However, one of the publications (Gowayed, 1995) has discussed both transverse and axial thermal conductivity of a carbon fiber composite. A non-linear increase in the thermal conductivity was reported with the increase of fiber volume fraction of plain weaves and no theoretical models are able to predict this non-linearity. The result of literature search even further identified the necessity and importance of carrying out the proposed research.

This review is focused on: 1) the concept of thermal conductivity, 2) experimental methods for measuring thermal conductivity of a composite material, and 3) analytical/numerical methods for predicting thermal conductivity of composite materials.

\subsection{Theory of thermal conductivity}

The theory of thermal conductivity was proposed by Fourier in 1822. According to Fourier, the fundamental heat conduction equation can be stated as "For a homogeneous solid, the local heat flux is proportional to the negative local temperature gradient”. For one dimensional steady state heat transfer, this statement can be represented by Equation 2.1:

$$
q^{\prime \prime}=-K \frac{d T}{d x}
$$


Where $\mathrm{q}$ is the heat flux, $\mathrm{K}$ is the thermal conductivity of the material, which is a positive $2^{\text {nd }}$ order tensor quantity, $d T / d x$ represents change in temperature across the thickness and negative sign indicates the temperature reduction from hotter surface to cooler surface.

According to Equation 2.1, conductivity can be given as (under the assumption, that heat is not lost in its plane)

$$
\mathrm{K}=(\mathrm{Q} / \mathrm{A}) /(\Delta \mathrm{T} / \Delta \mathrm{L})
$$

where $\mathrm{K}$ is the thermal conductivity (W/m-K), Q is the Heat Flux (W), A is the cross sectional area of the specimen $\left(\mathrm{m}^{2}\right), \Delta \mathrm{T}$ is the Temperature difference $(\mathrm{K}), \Delta \mathrm{L}$ is the over all distance $(\mathrm{m})$. Thus, the thermal conductivity of a material can be defined as a rate at which heat is transferred by conduction through a given unit area of a given material, when the temperature gradient is normal to the cross sectional area. The thermal conductivity of a composite material depends on the fiber, resin materials, fiber volume fraction, orientation of the fiber, direction of heat flow and operating temperature.

\subsection{Factors affecting thermal conductivity of composite materials}

Thermal conductivity of composites is anisotropic in nature. The knowledge of thermal conductivity of composites is needed for accurate design. Data about thermal conductivity of resin facilitates to reduce stresses related to shrinkage of composites during cure and mismatch in thermal expansion coefficients. Before conducting experiments to determine thermal conductivity of various composites, knowledge about effect of different parameters influencing thermal conductivity is essential.

\subsubsection{Fibers}

Fiber is the reinforcing phase of a composite material. Thermal conductivity of a composite depends upon the thermal conductive nature of the fiber and matrix. Commonly used fibers for composites include Glass, Carbon, and Aramid etc.

Glass fibers are commonly used for engineering composites. Their uses include the manufacturing of automotive parts, pipes, structural members etc. Glass fiber is available economically in abundance with good mechanical properties; thus widely used in composite structures (Barbero, 1998). Basing upon different applications glass fiber (silica-oxygen network) is classified into E glass, C glass, and S glass fibers (Barbero, 1998). E glass is used as 
an insulator and mostly used in electrical industry, hence got the name "E" before the word glass. E-glass also has good mechanical properties in addition to low cost and ease of usability. The letter "S" in S-glass stands for structural applications. S-glass got different chemical formulation and it has higher strength to weight ratio, and higher elongation strain percentage. S glass is a bit expensive and mostly used in structural application, and C-glass fibers are advantageous in resisting chemical corrosion. Glass fibers are available in different forms like continuous, chopped and woven fabrics.

The microstructure of any fiber plays vital role in carrying heat. The glass fiber has an amorphous structure. It consists of $\mathrm{SiO}_{2}$ molecules and forms a three dimensional silica polyhedral network along the length of the fiber. It behaves nearly isotropic, resulting in nearly same conductivity properties in any direction of the fiber.

Carbon fibers are manufactured using precursor materials like rayon, petroleum or coal tar pitches and polyacrylonitrile (PAN) (ASM Handbook, 2001). The conversion of pitch or PAN precursor to carbon fibers involves manufacturing steps like fiber formation by spinning, stabilization to thermoset the fiber, carbonization, graphitization, surface treatment and sizing (Mirmira, 1999). During graphitization stage at higher temperatures the crystallites are properly ordered and oriented along the axis direction of the fiber. In PAN based carbon fibers, during the graphitization stage the linear structure of carbon atoms transforms into a planar structure called as basal planes and are oriented or stacked along the axis of the fiber. These basal planes are closely packed and are responsible for the high modulus and higher electrical and thermal conductivities along the axis of the fiber.

Natural fibers are becoming potential alternatives for glass fiber reinforced composites in many applications (Joshi et al 2004). Usage of natural fibers like hemp, jute, flax, cotton etc. instead of synthetic fibers leads to increase in specific properties like impact strength, crash behavior, sound absorption, thermal insulation and reduction in component's weight, pollutants, and greenhouse gas emissions making the composite more environmental friendly. Natural fiber composites have many applications including automobile parts like door trim panels, headliners or back panels. Natural fiber is filled with cellulose material, which acts as an insulator, thus a natural fiber composite shows much lesser thermal conductivity when compared to a glass fiber reinforced polymer (GFRP) composite. 


\subsubsection{Resins}

Matrix materials are of different types like metal matrix, ceramic matrix and polymer matrix. Polymer matrices are most commonly used because of cost efficiency, ease of fabricating complex parts with less tooling cost and they also have excellent room temperature properties when compared to metal, ceramic matrices.

Polymer matrices can be either thermoplastic or thermoset. Thermoplastic materials are formed by addition polymerization. Thermoplastics soften or fuse when heated, harden and become rigid after cooling. Unlike thermosets, thermoplastics can be modified or reused upon the need. Thermoplastics have longer shelf life and higher fracture toughness than thermoset resins. Thermoplastic resins have high viscosity and less creep resistance when compared to thermosets (Barbero, 1998).

Thermoset matrices are formed due to an irreversible chemical transformation of a resin into an amorphous cross-linked polymer matrix. Due to huge molecular structures, thermoset resins provide good electrical and thermal insulation. Thermosets have low viscosity, which allow proper fiber wet out, excellent thermal stability and better creep resistance. The most commonly used thermoset resins are epoxy, polyester, vinyl ester and phenolics. Mostly thermoset resins can be formulated to give a wide range of properties upon the requirement.

Epoxy resin has excellent adhesion property compared to other resins. In addition to that it has low shrinkage upon curing, good chemical resistance, excellent mechanical properties. Epoxies have been used for advanced composites due to their adhesion to wide variety of fibers, with superior mechanical and electrical properties, good performance at elevated temperatures. Epoxies are expensive compared to polyester and less resistant to moisture. Polyester has the advantages of low cost, ease of handling, good chemical resistance with reasonable mechanical properties. Polyester and epoxy makes approximately $85 \%$ of the fiber reinforced polymer composites.

Vinyl ester has the chemical backbone of epoxy and curing mechanism of polyester, so it got improved resistance to chemical attack and ease of fabrication. Vinyl ester is stronger than polyester and less expensive than epoxy. Vinyl ester has better resistance to moisture absorption than polyester and the bonding capability is not good when compared to epoxy to all kinds of fibers. Vinyl ester offers good mechanical properties and excellent corrosion resistance. The bonding ability of vinyl ester is good to glass fiber but less efficient with carbon or Kevlar. Phenolic resin cures through condensation reaction, which produces water during the reaction. It 
has excellent properties like high temperature and creep resistance, good thermal insulation and sound damping properties in addition to first-rate fire properties.

\subsubsection{Fillers}

The primary advantage of using filler material in composites is to reduce the overall cost of the composite. In addition to reduction of cost, filler materials also serve as major ingredient, which improves the performance of the composite by enhancing crack resistance, reducing shrinkage, influencing mechanical strength, improving fire resistance etc. Major filler materials used in composite manufacturing are calcium carbonate, kaolin (clay), Aluminum-trihydrate etc.

\subsubsection{Additives}

Additive materials are primarily used to modify and tailor material properties of the composite. By introducing additives into resin system it enhances the processability or durability of the composite. Additives help in increasing the performance or a specific property as well it increases the overall cost of the product. Various additives widely used to boost the thermal and electrical conductivity of the resin are graphite powder, chopped carbon fiber, carbon nano-tubes etc.

\subsubsection{Manufacturing Methods}

As the thermal conductivity of a polymer composite is based upon the conductivity of fiber and resin, being a polymer, resins are usually insulating and the conductivity is dominated by fiber material. The compactness of fibers per unit area influences the conductivity of the composite. Fiber packing in a composite depends on the method of manufacturing. The various composites manufacturing techniques are Hand lay-up, Compression molding, Resin Transfer Molding, Pultrusion etc (Barbero, 1998).

\subsubsection{Hand lay-up}

Hand lay-up is the oldest and simplest method of manufacturing composites. The tools required for the process are a mold to accommodate dry manufacturing according to the desired shape and a roller to facilitate uniform distribution of resin. Virtually any sized composites can be manufactured using this method. This method is the cheapest method of manufacturing but it has some disadvantages such as long curing time, low production rate, and further the quality of the composite depends on the skill of the worker. 


\subsubsection{Compression molding process}

This method is commonly used to manufacture sheet molding or bulk molding. Compression molding machine consists of a male and female dies or platens to form the mold. The reinforcement combined with resin is placed in the mold and a hydraulic press is used to apply high pressure by closing male and female halves of the mold. After the material is cured, the pressure is released and the part is removed from the mold. Exterior body panels for structural members such as automobile bumpers are widely manufactured using this method.

\subsubsection{Resin Transfer Molding (RTM)}

This manufacturing method uses a mold with an inlet to introduce resin/catalyst mixture and vent ports to allow air to escape. In this method, resin and catalysts are mixed proportionally in an injection head and then pumped into the mold. Dry reinforcement is placed inside the mold and is closed. Resin is pumped into the mold till the mold is full. After the resin is cured, the part is removed from the mold. RTM has been further modified by using vacuum to suck resin catalyst mixture inside. In this case, vacuum bags are used along with molds and hence this method is called as Vacuum Assisted Resin Transfer Molding (VARTM). VARTM process enhances resin flow and reduces void fraction. RTM process is cleaner with less emissions of volatiles. The applications of this process includes manufacturing of auto body panels, swim pool panels, sandwich panels etc. A schematic of Resin Transfer Molding is shown in Figure 2.1

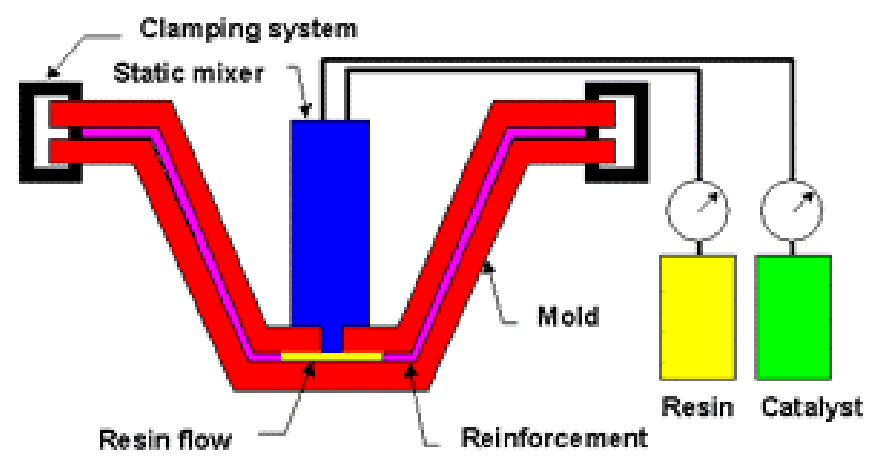

Figure 2.1 Schematic of Resin Transfer Molding (Photo Courtesy: http://www.esi-group.com)

\subsubsection{Pultrusion}

Pultrusion is a continuous and highly automated molding process used in fabrication of composite parts that have a constant cross section. Reinforcement materials are arranged in such a pattern so that they match the profile of the die. The fibers are pulled through a resin bath and 
then to the heated metal pultrusion die. The die is maintained at a précised temperature so that it can transfer heat to the fiber and liquid resin. The heat energy is used to carry on the polymerization of the resin to matrix. The cooled solid part is then pulled from the die and cut to desired length. Pultrusion is a low cost process for a large volume production. Applications of this process are in the fields like construction, transportation, electrical etc. A schematic of pultrusion process is shown in Figure 2.2

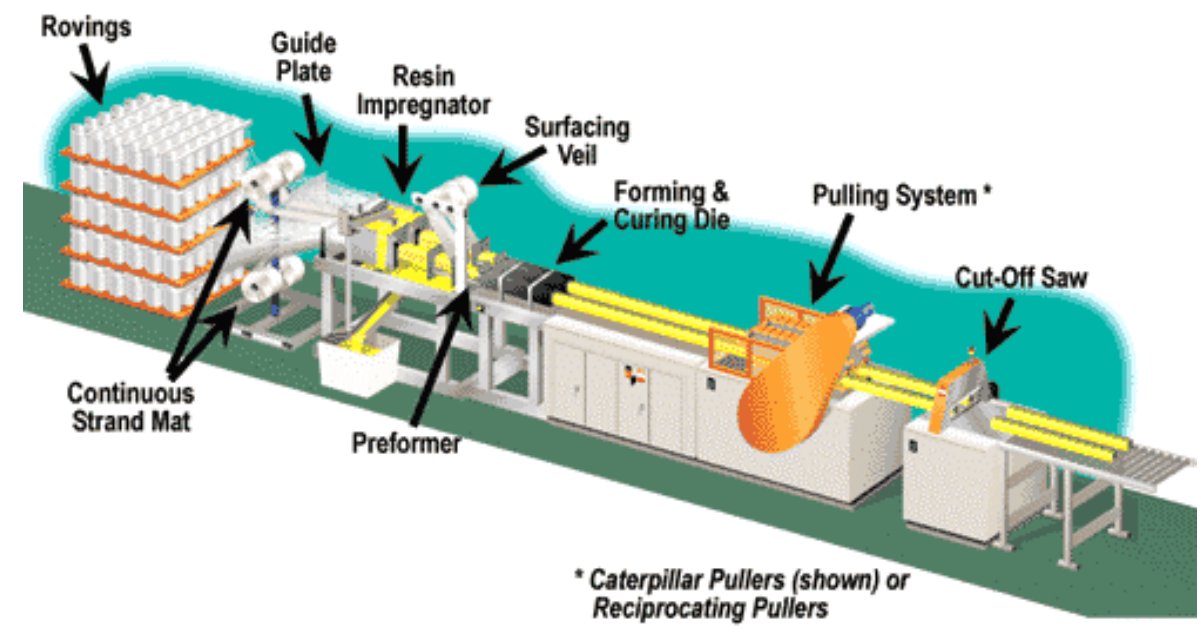

Figure 2.2 Schematic of Pultrusion Process

(Photo Courtesy: www.pulwellpultrusions.com)

\subsection{Experimental approach for thermal conductivity measurements}

There are various test methods available for thermal conductivity measurement and each method depends mainly on configuration of a material and job requirement. Some principal experimental methods for determinations of thermal conductivity are discussed below:

\subsubsection{Guarded heat flow meter}

This method is based on two dimensional steady state techniques and is used to measure and compare thermal properties of materials under controlled conditions and their ability to maintain required thermal conductance levels (ANTER, 2003).

The specimen and a heat flux transducer (HFT) are sandwiched between two flat plates controlled at different temperatures, to produce a heat flow through the stack. A cylindrical guard surrounds the test stack and is maintained at a uniform mean temperature of the two plates, in order to minimize the lateral leak of heat. At steady state, the difference in temperature between the surfaces contacting the specimen is measured with temperature sensors embedded in the 
surfaces, together with the electrical output of the HFT. The output voltage is proportional to the heat flow through the specimen, HFT and the interfaces between the specimen and the apparatus. The coefficient of thermal conductivity can be obtained by prior calibration of system with the specimens of know thermal conductivity.

At equilibrium, the thermal conductivity of material can be given as

$$
\begin{gathered}
\mathrm{K}=(\Delta \mathrm{x}) / \mathrm{R}_{\mathrm{s}} \\
\mathrm{R}_{\mathrm{s}}=(\mathrm{N}(\Delta \mathrm{T}) / \mathrm{Q})-\mathrm{R}_{\mathrm{o}}
\end{gathered}
$$

where $\mathrm{K}$ is the thermal conductivity $(\mathrm{W} / \mathrm{m}-\mathrm{K}), \mathrm{R}_{\mathrm{s}}$ is the resistance of unknown specimen $\left(\mathrm{m}^{2}\right.$. $\mathrm{K} / \mathrm{W}$ ), $\mathrm{N}$ is the HFT calibration constant, $\Delta \mathrm{T}$ is the temperature difference between one surface of the specimen and the other surface $(K), \Delta x$ is the specimen thickness $(m)$, and $R_{0}$ is the contact thermal resistance.

Other methods also based on two dimensional steady state techniques for wide range of operating temperatures include Heat Flow Meter, Guarded Hotplate, Hot Wire, and Laser Flash.

\subsubsection{Surface probe method}

The surface probe (also called Mathis probe) is demonstrated as a non-intrusive indirect method of obtaining thermal conductivity (Rouison et.al, 2002) for heat flux parallel (i.e., axial or transverse) to the plane of a sample. This transient-state probe consists of three parallel nickel ribbons connected to electrical circuitry providing a constant rate of heating with time, with the outer strips acting as thermal guards, forcing the heat flux vector to be perpendicular to the probe surface. The circuitry is designed to monitor the temperature of the central strip, and computer control and data acquisition allows the recording of temperature rise of the central strip and the time lapse after the start of heating. When placed against a flat sample surface, this temperature rise depends on the thermal properties of the sample.

$$
\mathrm{T} \alpha\left(\mathrm{Qt}_{1 / 2}\right) /(\mathrm{k} \rho \mathrm{Cp})
$$

where $\mathrm{T}$ is surface temperature, $\mathrm{Q}$ is center strip constant heating source intensity in $\mathrm{W} / \mathrm{m}^{2}, \mathrm{t}$ is time elapsed after the onset of heating, $\mathrm{k}, \rho$, and $\mathrm{Cp}$ are thermal conductivity, density, and heat capacity of the sample. This gives $\mathrm{K}$ for the heat flux vector normal to the plane of the surface. 


\subsubsection{Transient pulse method}

This method deals with the usage of electrical model, which detects the dissipations of thermal system (Zmeskal et.al 2003). A thermo physical transient tester is used to detect the pulse heat responses. In this method, the sample is placed in the isothermal chamber, consisted of the three parts of cylindrical shape. Between the first and the second part the heat source was placed (nickel folium $20 \mu \mathrm{m}$ thick and radius $R_{2}=2 \mathrm{~cm}$ ). Between the second and third part one connection of differentially connected thermocouple (Ni Cr-Ni) was placed. The second connection was placed on heat exchanger where the constant temperature was kept with the help of thermostat. The temperature is measured in terms of the platinum resistance. Heat is supplied as a rectangular current pulse from the software directed source and the responses are computed from the parameters of pulse. The change of temperature was measured by nano voltmeter. This method is schematically illustrated in Figure 2.3.

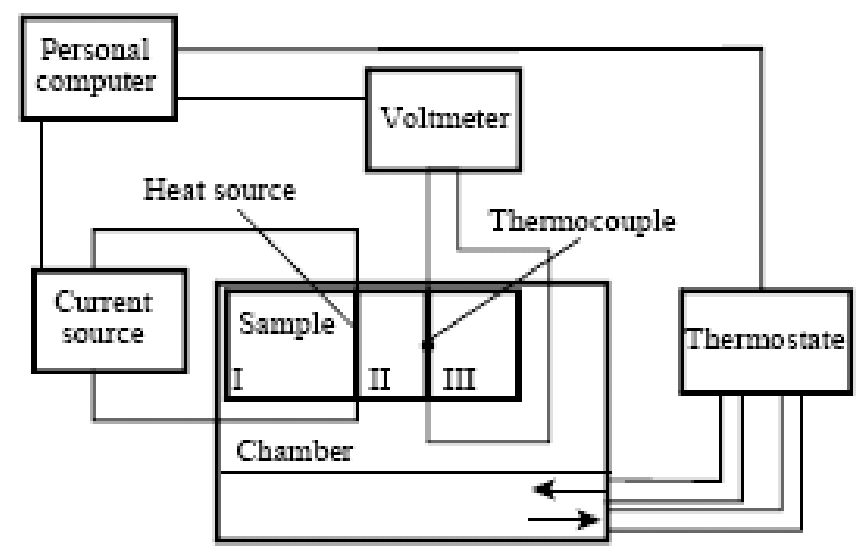

Figure 2.3 Schematic representation of transient pulse method

The thermal conductivity equation can be given as

$$
\lambda=a c \rho=\frac{Q h}{2 \Delta T_{m} \Delta t_{m} \sqrt{2 \pi \mathrm{e}}} \frac{f_{c}}{f_{a}}
$$

where $h$ is sample thickness, $\rho$ is density of material and $\Delta T_{m}$ is maximal temperature response for applicated thermal pulse; it will occurs in the time $\Delta t_{m}$ after start of heating. 


\subsubsection{Flash pulse measurement system}

Flash Pulse technique is a direct method of measuring the off axis thermal conductivity of a composite and was first developed by Parker and Jenkins (Parker et al, 1961). A face of the FRP sample will be exposed to the short pulse of radiant energy and the thermal diffusivity of the sample is determined by considering the travel time of heat pulse through the section of the sample. The thermal diffusivity was given as

$$
\alpha=\frac{1.38 L^{2}}{\pi^{2} t_{1 / 2}}
$$

where $\mathrm{L}$ is the thickness of the sample, $\alpha$ is the thermal diffusivity, and $t_{1 / 2}$ is the time required to reach one half of the maximum back surface temperatures. Thermal conductivity is given by

$$
\mathrm{K}=\alpha \rho \mathrm{C}_{\mathrm{p}}
$$

where $\mathrm{K}$ is the thermal conductivity, $\rho$ is the density of the material and $\mathrm{C}_{\mathrm{p}}$ is the specific heat of the sample. So the thermal conductivity can be given as

$$
\mathrm{K}=\frac{1.38 \rho C_{p} L^{2}}{\pi^{2} t_{1 / 2}}
$$

An experimental set up is schematically represented in Figure 2.4.

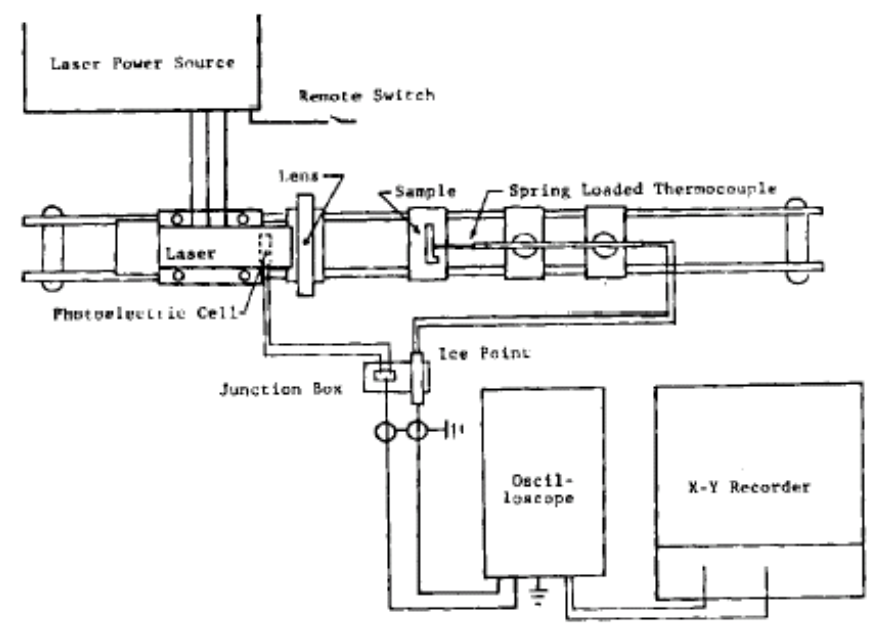

Figure 2.4 Schematic representation of Laser Pulse Operator 


\subsection{Theoretical approach for thermal conductivity predictions}

The theoretical approach brings more generalized equation for a two dimensional steady state heat flow. Various theoretical approaches are used to yield the thermal conductivity of a composite material so that the heat flow in anisotropic composite material in any direction can be estimated.

\subsubsection{The rule of mixture and finite difference method}

For homogeneous fibers of thermal conductivity $\mathrm{K}_{\mathrm{f}}$ embedded in a resin matrix of thermal conductivity $\mathrm{Km}$, the thermal conductivity $\mathrm{K}_{\mathrm{p}}$ parallel to the axis of the fiber is given by (Barbero, 1998)

$$
\mathrm{K}_{\mathrm{p}}=\mathrm{K}_{\mathrm{f}} \mathrm{V}_{\mathrm{f}}+\left(1-\mathrm{V}_{\mathrm{f}}\right) \mathrm{K}_{\mathrm{m}}
$$

where $V_{f}$ is the fiber volume fraction while the thermal conductivity in transverse direction $\left(\mathrm{K}_{\mathrm{t}}\right)$ can be given as

$$
1 / \mathrm{K}_{\mathrm{t}}=\mathrm{V}_{\mathrm{f}} / \mathrm{K}_{\mathrm{f}}+\left(1-\mathrm{V}_{\mathrm{f}}\right) / \mathrm{K}_{\mathrm{m}}
$$

However, Equation 2.11 developed by rule of mixtures gives the lower limit value of the transverse thermal conductivity. The upper limit value can be give as (James et.al, 1987)

$$
\mathrm{K}_{\mathrm{t}}=\mathrm{BK}_{\mathrm{m}}\left(1-\mathrm{V}_{\mathrm{f}}\right)+\left(\mathrm{V}_{\mathrm{f}}+(1-\mathrm{B})\left(1-\mathrm{V}_{\mathrm{f}}\right) \mathrm{K}_{\mathrm{f}} \mathrm{K}_{\mathrm{m}}\right) /\left(\mathrm{V}_{\mathrm{f}} \mathrm{K}_{\mathrm{m}}+(1-\mathrm{B})\left(1-\mathrm{V}_{\mathrm{f}}\right) \mathrm{K}_{\mathrm{f}}\right) \quad 2.12
$$

In finite difference method the body in which the heat flow occurs is divided into equal increments in both $\mathrm{x}, \mathrm{y}$ directions creating nodal points in both the directions. According to the finite difference method the temperature around a nodal point is related to the thermal conductivity for the material link between nodes as

$$
\mathrm{Ti}=\left(\Sigma \mathrm{j}=1,4 \mathrm{~K}_{\mathrm{j}} \mathrm{T}_{\mathrm{j}}\right) /\left(\Sigma \mathrm{j}=1,4 \mathrm{~K}_{\mathrm{j}}\right)
$$

Where $\mathrm{K}_{\mathrm{j}}$ is the thermal conductivity between the nodes. Equation (2.13) is applied sequentially to all nodes of a body using the latest calculated values and the process is repeated until a steady state equation is obtained by Gauss-Seidel iteration. 


\subsubsection{Caruso model}

A general finite element analysis method was proposed by Caruso et al (1986) to predict thermal conductivity of a composite. This method is based on integrating Advanced Finite Element Methods with simplified micromechanics equations. The boundary conditions and loading conditions i.e. change in temperature and thermal expansions were considered in the derivation of equation to predict thermal conductivity.

The longitudinal and transverse conductivity equations were given as

$$
\begin{aligned}
& \mathrm{K}_{\mathrm{L}}=\mathrm{V}_{\mathrm{f}} * \mathrm{~K}_{\mathrm{fl}}+\mathrm{V}_{\mathrm{m}} \mathrm{K}_{\mathrm{ml}} \\
& \mathrm{K}_{\mathrm{T}}=1-\sqrt{V_{f}} K_{m}+\frac{\sqrt{\mathrm{V}_{\mathrm{f}}} * \mathrm{~K}_{\mathrm{m}}}{1-\sqrt{\mathrm{V}_{\mathrm{f}}}\left(1-\frac{\mathrm{K}_{\mathrm{m}}}{\mathrm{K}_{\mathrm{fl}}}\right)}
\end{aligned}
$$

Where $\mathrm{K}_{\mathrm{L}}$ is the thermal conductivity in longitudinal direction, $\mathrm{K}_{\mathrm{T}}$ is the thermal conductivity in transverse direction, $\mathrm{V}_{\mathrm{f}}$ is the fiber volume fraction, $\mathrm{V}_{\mathrm{m}}$ is the matrix volume fraction, $\mathrm{K}_{\mathrm{fl}}$ and $\mathrm{K}_{\mathrm{ml}}$ are thermal conductivity in longitudinal direction of fiber and matrix, respectively.

\subsubsection{Muralidhar model}

Muralidhar (1989) proposed an analytical model using FE modeling and analytical formulation to predict thermal conductivity as a function of fiber volume fraction. The author considered the fibers in the composite materials as inhomogeneous insulating layers and thus the thermal conductivity of the fiber to be zero along with the sidewalls between the reinforcements in the composite material. Herein, only the transverse thermal conductivity of the composite material was modeled while the longitudinal thermal conductivity can be obtained by rule of mixtures effectively.

In this method the formulation was given by considering the transient heat conduction. The steady heat conduction was given by the Laplace equation

$$
\nabla^{2} \mathrm{~T}=\mathrm{T}_{\mathrm{xx}}+\mathrm{T}_{\mathrm{yy}}=0
$$

and the unsteady case was given as

$$
\nabla^{2} \mathrm{~T}=\left(\frac{1}{\alpha}\right) \mathrm{T}_{\mathrm{t}}
$$


Where $\mathrm{T}$ is the temperature, $\mathrm{T}_{\mathrm{t}}$ is the partial differential of temperature with respect to time, and $\alpha$ is thermal diffusivity of matrix. The above equations were solved considering the boundary conditions and the transient temperature distribution through Laplace inversion method.

A best fit between classical rule of mixtures and empirical correlation for transverse conductivity to determine the transverse thermal conductivity was given as

$$
\mathrm{K}=1-1.63 \mathrm{~V}
$$

Where $\mathrm{K}$ is thermal conductivity and $\mathrm{V}$ is the fiber volume fraction in the range from 0 to 0.2 . It was found that the pattern of distribution of fibers and fineness of their size showed very little effect on thermal conductivity of composites.

\subsubsection{Cylinder assemblage model}

Cylinder Assemblage model was developed by Hashin (1979) who considered a transversely isotropic fiber reinforced cylinder in which the phases are transversely isotropic with material axes of symmetry in cylindrical axis direction. The transverse thermal conductivity was given as:

$$
K_{T}=K_{T M}\left\{\frac{\left(K_{T M} V_{M}+K_{T F}\left(1+V_{f}\right)\right)}{\left(K_{T M}\left(1+V_{f}\right)+K_{T F} V_{M}\right)}\right\}
$$

Where $\mathrm{K}_{\mathrm{T}}$ is the transverse thermal conductivity, $\mathrm{K}_{\mathrm{TM}}$ is the thermal conductivity of the matrix in transverse direction $V_{M}$ is the matrix volume fraction, $V_{f}$ is the fiber volume fraction, and $K_{T F}$ is the thermal conductivity of fiber in transverse direction.

The above equation was derived using the expressions for finding elastic moduli and thermal expansion coefficients of unidirectional fiber composites consisting of transversely isotropic phases.

\subsubsection{Shear loading analogy}

A shear loading analogy method was proposed by Springer and Tsai (1967) to estimate thermal conductivity of a composite. Herein, a numerical approach was presented based on analogy between the response of the unidirectional composite to shear loading and to heat transfer along with a thermal model. This model was developed under some assumptions regarding the placement of fibers and packing patterns like elliptical, cylindrical and square 
shapes. In particular, the matrix and fibers were assumed as parallel and series as in electrical circuits depending on the heat flow direction i.e., longitudinal or transverse, respectively.

The longitudinal conductivity was given as

$$
\mathrm{K}_{11}=\mathrm{V}_{\mathrm{f}} \mathrm{K}_{\mathrm{f}}+\mathrm{V}_{\mathrm{m}} \mathrm{K}_{\mathrm{m}}
$$

and the transverse thermal conductivity was given as

$$
\mathrm{K}_{22}=\mathrm{K}_{\mathrm{m}}\left[1-2 \sqrt{\frac{V_{f}}{\pi}}\right]+\frac{1}{B}\left[\pi-\frac{4}{\sqrt{1-\left(\frac{B^{2} V_{f}}{\pi}\right)}} \tan ^{-1}\left(\frac{\sqrt{1-\frac{B^{2} V_{f}}{\pi}}}{1+\sqrt{\frac{B^{2} V_{f}}{\pi}}}\right)\right]
$$

where $\mathrm{B} \equiv 2\left(\frac{K_{m}}{K_{f}}-1\right), \mathrm{K}_{11}$ and $\mathrm{K}_{22}$ are the longitudinal and transverse thermal conductivities respectively, $\mathrm{V}_{\mathrm{f}}$, and $\mathrm{V}_{\mathrm{m}}$ are the fiber volume fraction and matrix volume fraction respectively, $\mathrm{K}_{\mathrm{m}}$ and $\mathrm{K}_{\mathrm{f}}$ are the thermal conductivities of matrix and fiber respectively. The shear loading analogy approach under predicted thermal conductivity by about $10 \%$ depending on fiber volume fraction.

\subsubsection{Effective transverse thermal conductivity}

Mirmira (1999) defined the effective transverse thermal conductivity of a composite by considering the transverse anisotropy of the fiber (in cylindrical coordinates), interfacial thermal conductance between matrix and fiber, radius of fiber along with the volume fractions of the matrix, fiber and their thermal conductivities. Mori and Tanaka micromechanics model for heat conduction in composite material was used in order to derive the equation for calculating effective thermal conductivity. The other important parameters considered included effect of composite porosity and interaction between the fibers. In this approach the temperature profile for a single fiber was first considered and the analysis was extended to the entire composite.

The conventional rule of mixtures was considered for estimating the longitudinal effective thermal conductivity but the effective transverse thermal conductivity was given as 


$$
k_{e}=k_{m}\left[\frac{\left(\frac{\sqrt{k_{r} k_{\phi}}}{k_{m}}+\frac{\sqrt{k_{r} k_{\phi}}}{a h_{c}}+1\right)+V_{f}\left(\frac{\sqrt{K_{r} K_{\phi}}}{k_{m}}-\frac{\sqrt{k_{r} k_{\phi}}}{a h_{c}}-1\right)}{\left(\frac{\sqrt{k_{r} k_{\phi}}}{k_{m}}+\frac{\sqrt{k_{r} k_{\phi}}}{a h_{c}}+1\right)+V_{f}\left(\frac{\sqrt{k_{r} k_{\phi}}}{a h_{c}}-\frac{\sqrt{k_{r} k_{\phi}}}{k_{m}}+1\right)}\right]\left(1-V_{p}\right)^{2}
$$

where $k_{e}$ is the effective thermal conductivity in transverse direction, $k_{m}$ is the thermal conductivity of matrix, $k_{r}$ is the thermal conductivity of fiber in radial direction, $K_{\phi}$ is the thermal conductivity of fiber in tangential direction, $V_{f}$ is the fiber volume fraction, $a$ is the fiber radius, $h_{c}$ is the interfacial thermal conductance between fiber and matrix, $V_{p}$ is the porosity volume fraction.

\subsubsection{Bounding solution approach}

In order to determine effective thermal conductivity value of a composite with unknown phase geometry parameter, Lim (2002) developed a boundary solution method. In this method a lower and upper bounds were concluded for the effective thermal conductivity of a composite material.

The bounds were determined by considering a representative volume element and considering its geometry in three directions $\mathrm{X}, \mathrm{Y}, \mathrm{Z}$. This bounding solution technique has considered various geometrical assumptions in the reinforcements like unidirectional both in longitudinal and transverse, particulate, in plane and out of plane laminae etc. The bounds were given as

$$
\frac{k_{c 1}}{k_{m}}=\left\{1-V_{f}^{1-R}\left[1-\frac{1}{1-V_{f}^{R}\left[1-\frac{k_{f}}{k_{m}}\right]}\right]\right\}^{-1}
$$

and

$$
\frac{k_{c 2}}{k_{m}}=\left\{1-V_{f}^{R}\left[1-\frac{1}{1-V_{f}^{1-R}\left[1-\frac{k_{m}}{k_{f}}\right]}\right]\right\}^{+1}
$$


where, $k_{c 1}, k_{c 2}$ are the lower and upper bounds of the thermal conductivity in a composite $V_{f}$, is the volume fraction of fiber and $k_{m}, k_{f}$ are the thermal conductivity of matrix and fiber respectively. $\mathrm{R}$ corresponds the reinforcement parameter such that $\mathrm{R}=1,2 / 3,0$ for unidirectional fiber, particulate and laminae reinforcements respectively for thermal conductivity in parallel to reinforcement axis of symmetry and $\mathrm{R}=1 / 2,2 / 3$ and 1 for unidirectional fiber, particulate and laminae reinforcements respectively, for transverse to the reinforcement axis of symmetry. 


\section{CHAPTER 3}

\section{TESTING METHODS}

\subsection{Introduction}

This chapter presents the development of an experimental method for thermal conductivity measurements of composite materials in transverse, longitudinal and through the thickness directions. After a brief description on the test equipment, the operation principle of the unit is discussed and followed by sample requirement and testing procedure. This chapter also includes the methods to find fiber volume fractions of the samples tested for determining the thermal conductivity values.

\subsection{Experimental setup}

A guarded heat flow meter method has been developed for thermal conductivity measurements. This is achieved by using a thermal conductivity testing system Unitherm model 2022 from ANTER Corp., Pittsburgh, PA. The experimental set up of this instrument in CFCWVU laboratory is shown in Figure 3.1.

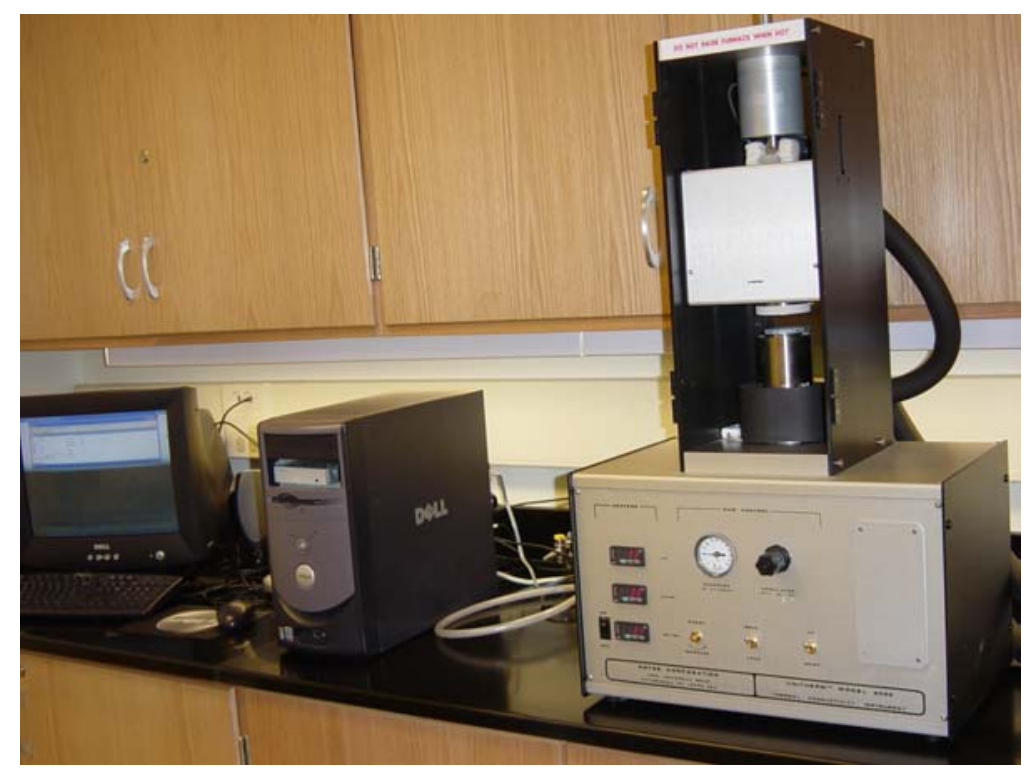

Figure 3.1 Experimental set up of Unitherm 2022 
This unit is supplied with a mid range flux module covering a thermal resistance range from 0.002 to $0.02 \mathrm{~m}^{2} \mathrm{~K} / \mathrm{W}$ and is able to measure the thermal conductivity of materials in the range of 0.1 to $40 \mathrm{~W} / \mathrm{m}-\mathrm{K}$ in terms of test standard ASTM E 1530 . The materials that can be tested include metals, ceramics, polymers, composites, glass etc. The test samples need to be prepared in a form of two-inch diameter circular discs with their thickness depending on the materials' thermal conductivity. The thermal conductivity machine was supplied with three sets of calibration samples span the $R_{s}$ range from 0.0005 to $0.05 \mathrm{~m}^{2} \mathrm{~K} / \mathrm{W}$. These samples were tested for conductivity values and compared with the given values by the manufacturer for calibration purpose. The relationship among the thermal conductivity of a material, its thermal resistance and sample thickness is discussed in detail under Section 3.3.

This equipment requires compressed air to raise and lower the upper stack assembly. It also needs either city water or a chiller to cool the heat sink, giving an operation temperature range from $20^{\circ} \mathrm{C}$ to $300^{\circ} \mathrm{C}$. ANTER model Unitherm 2022 is a computerized system. The computer automatically controls the equipment for testing and data processing through a latest version of electronics and operating software once a test program is designed and initiated.

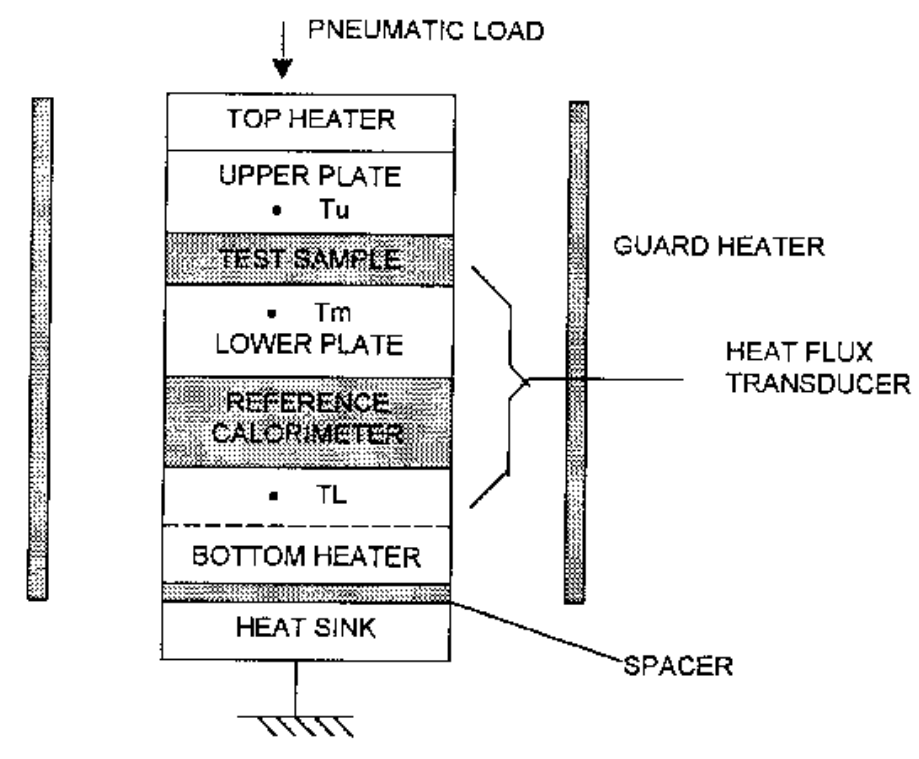

Figure 3.2 Schematic model showing the system arrangement in Unitherm 2022

A schematic picture shown in Figure 3.2 represents the system functioning in detail. The assembly is a stack of parts with different functionalities. The heater on top and bottom helps to maintain steady state heat transfer through the sample, two polished surfaces on top and bottom of the sample transfer heat from top and bottom heaters with reduced thermal resistance through 
surface. A reference calorimeter is placed under the lower plate, which acts as a heat flux transducer. The heat sink at the bottom avoids excessive temperature from the system. The sample is compressed in between the polished surfaces, each controlled at different temperatures, using pneumatic load. The pressure is maintained at 10 psi using pressurized air supply. As an option, coolant water is circulated through heat sink. A circular low temperature heat insulation ring is wrapped around the lower stack of the assembly to restrain heat flow to outside atmosphere. The entire system is maintained in a thermally insulated glass chamber. Unitherm is completely automatic while testing as the apparatus is completely controlled by a computer. The test system is hooked to the computer by means of an USB cable.

Considering the operation of the system, the sample to be tested is prepared into a flat surface on both sides and thermal compound is applied on the sample to reduce thermal resistance caused due to surface roughness. Then the prepared sample is placed in between two polished surfaces and a pneumatic pressure of $10 \mathrm{psi}$ is applied on the top portion of the stack. The sample can be tested in the temperature range from $20^{\circ} \mathrm{C}$ to $300^{\circ} \mathrm{C}$. For steady state heat transfer, the user can divide the testing into different zones, called as set point temperatures. In this thesis the testing was divided into three temperature zones i.e. $60,80,100^{\circ} \mathrm{C}$. For higher thermal conductivity materials, a difference of 50 degrees is recommended for the machine. At every set point temperature, the system checks for steady state heat flow through the sample and thermal conductivity is measured.

\subsection{Operation principle of Unitherm 2022}

By definition thermal conductivity means "The material property that describes the rate at which heat flows with in a body for a given temperature change." For one-dimensional heat conduction the formula can be given as Equation 3.1

$$
Q=K A \frac{T_{1}-T_{2}}{x}
$$

Where $\mathrm{Q}$ is the heat flux (W), $\mathrm{K}$ is the thermal conductivity (W/m-K), A is the cross- sectional area $\left(\mathrm{m}^{2}\right), \mathrm{T}_{1}-\mathrm{T}_{2}$ is the difference in temperature $(\mathrm{K}), \mathrm{x}$ is the thickness of the sample $(\mathrm{m})$.

The thermal resistance of a sample can be given as Equation 3.2

$$
R=\frac{T_{1}-T_{2}}{Q / A}
$$


Where $R$ is the resistance of the sample between hot and cold surfaces $\left(\mathrm{m}^{2}-\mathrm{K} / \mathrm{W}\right)$.

From Equations 3.1 and 3.2 we can derive that

$$
K=\frac{x}{R}
$$

In Unitherm 2022 the heat flux transducer measures the Q value and the temperature difference can be obtained between the upper plate and lower plate. Thus the thermal resistance can be calculated between the upper and lower surfaces. Giving the input value of thickness and taking the known cross sectional area, the thermal conductivity of the samples can be calculated using Equation 3.3.

\subsection{Sample requirement and test procedure}

Preparation of test sample is a challenging task. One accurate measurement requires a sample of dimensional precision of \pm 0.005 inch both in diameter and thickness. A core drill is employed to cut a two-inch diameter disk and then the disk is machine-milled to appropriate thickness.

A sample thickness is determined by the relationship between thickness, resistance and thermal conductivity as defined by Equation 3.3. By assigning an estimated thermal conductivity value to the testing material specimen with a given thickness, the calculated thermal resistance should fall into the working window of the equipment, which is 0.002-0.02 $\mathrm{m}^{2} \mathrm{~K} / \mathrm{W}$ for ANTER Unitherm model 2022. The thickness usually can be considered any value between $50 * \mathrm{~K}$ to $0.5^{*}$ $\mathrm{K}(\mathrm{mm})$ with $25 \mathrm{~mm}$ being the maximum thickness for Unitherm model 2022.

A test begins from sample preparation. Major operation procedures include: 1) application of thermal compound onto sample surface to reduce the interfacial resistance; 2) proper loading of sample into the stack assembly so that it completely occupies the gap between upper and lower stacks; 3 ) closing the furnace chamber and mounting on protective glass shield; 4) switch on air and water supply; 5) designing of a test program that need input of sample thickness and temperature segments; 6) switching on heaters before starting a test; 7) after testing, allowing the unit to cool down to room temperature before removing the protective shield; 8) cleaning the upper and lower stacks; and 9) data processing. Typically a three-segment test lasts for three hours. 


\subsection{Determination of fiber volume fraction}

Fiber volume fraction of a composite can be calculated using two methods.

1) Burn out method, and 2) Areal method.

\subsubsection{Burn-out method}

The fiber volume fraction for composites with inorganic fibers such as glass can be determined by using the standard test method for Ignition loss of cured resins, ASTM D 2584. Using this method, samples with dimensions 1" $\mathrm{x} 1$ " are placed in a crucible and weighed, which are then placed in a furnace to attain a temperature of $565^{\circ} \mathrm{C}$ for three hours, which is sufficient to burn off the matrix material. After the matrix is burned off, the remaining fiber is weighed. Using the fiber, resin densities and fiber weight fraction the fiber volume fraction can be determined.

\subsubsection{Areal Method}

Areal method is used where organic fibers like carbon burns along with the resin. In this method the volume of the specimen is calculated using the mass and density of the specimen or by determining the dimensions of the specimen. The mass of the fiber is calculated by determining the number of layers of fabric in the specimen and weight of each layer. The fiber volume can be calculated by using mass of fiber and density of fiber. Finally the fiber volume fraction is determined by using fiber volume divided by volume of specimen.

For samples like carbon composites, determining the number of layers per unit thickness after burning may not be accurate as there is a possibility of burning some of the layers while burning off the matrix. To avoid this problem, the specimen was observed under Scanning Electron Microscope (SEM) to count the number of layers per unit thickness of 1"x 1". Three different samples were considered as representative volume elements from three different locations of the sample and observed under SEM. To observe a sample under SEM, the sample has to be surface finished using different ranges of polishing papers to obtain a clear image of the sample. In the present study, a total of 18 different pictures were taken using SEM and counted for number of layers. Typical pictures taken for two different samples were shown in Figure 3.3. 

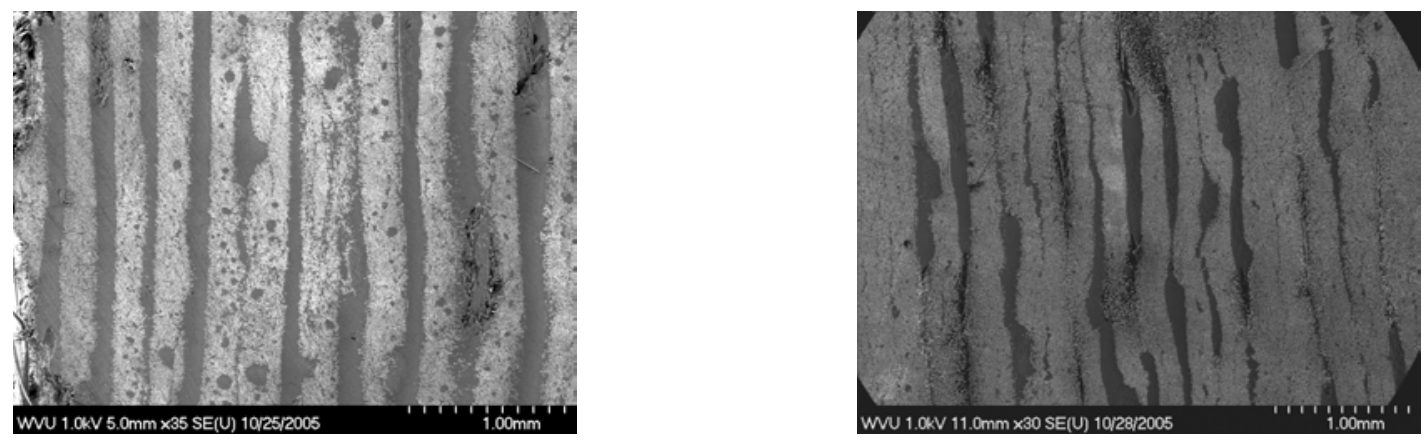

Figure 3.3 SEM pictures showing the number of layers and their alignment 


\section{CHAPTER 4}

\section{MATERIALS AND SAMPLE PREPARATION}

\subsection{Introduction}

The objective of this investigation is to determine conductivity properties of FRP composites in three different directions (i.e. longitudinal, transverse, and through-the-thickness). The properties are function of composition parameters and process parameters. Herein, the thermal conductivity measurement in the transverse direction means that a sample is prepared in such a way that heat flow direction is transverse to primary fiber orientation of the sample;

similarly, the thermal conductivity measurement in the longitudinal direction means heat flowing along the fiber direction; and the thermal conductivity measurement in the thickness direction means heat flowing through the thickness direction. The thermal conductivity of an anisotropic composite material depends on the resin nature, fiber type and architecture, fiber volume fraction, manufacturing technique, direction of heat flow and operating temperature, leading to a high degree of complexity.

\subsection{Thermal conductivity test matrix}

The research proceeded as outlined in Table 4.1, Thermal Conductivity Test Matrix. The test matrix has included various material parameters and process parameters, leading to a spectrum of composite samples for their thermal conductivities along $0^{0}$ and $90^{\circ}$ fiber orientations and through the thickness direction. It should be noted that sample preparation was the most challenging part of the entire process. Many tools were used specially for sample preparation such as carbide grit, carbide tipped hole-saw, and diamond tipped hole-saw. In addition, attention to environmental and health safety issues were also needed. 
Table 4.1 Thermal Conductivity Test Matrix

\begin{tabular}{|c|c|c|c|c|c|c|c|c|c|c|c|c|c|c|}
\hline \multicolumn{15}{|c|}{ Effect of different materials and manufacturing methods } \\
\hline \multicolumn{6}{|c|}{ Pultrusion } & \multicolumn{9}{|c|}{ Compression Molding/Hand lay-up/RTM } \\
\hline \multicolumn{3}{|c|}{$4 "$} & \multicolumn{3}{|c|}{$8 "$} & \multicolumn{3}{|c|}{ Glass } & \multicolumn{3}{|c|}{ Carbon } & \multirow{2}{*}{$\begin{array}{c}\begin{array}{l}\text { Vinyl } \\
\text { ester }\end{array} \\
\text { Th }\end{array}$} & \multirow{2}{*}{$\begin{array}{c}\text { Polyester } \\
\mathrm{Th}\end{array}$} & \multirow{2}{*}{$\begin{array}{c}\text { Epoxy } \\
\text { Th }\end{array}$} \\
\hline \multicolumn{3}{|c|}{$\mathrm{Th} / \mathrm{F}, \mathrm{W}$} & $\mathrm{L} / \mathrm{F}$ & $\begin{array}{c}\mathrm{Tr} / \\
\mathrm{F}\end{array}$ & $\begin{array}{c}\text { Th/ } \\
\text { F,W }\end{array}$ & $\mathrm{L}$ & $\mathrm{T}$ & Th & $\mathrm{L}$ & $\mathrm{T}$ & Th & & & \\
\hline \multicolumn{6}{|c|}{ Vinyl ester, Multi-axial glass fabric } & \multicolumn{3}{|c|}{$\begin{array}{c}\text { Vinyl ester, } \\
0 / 90\end{array}$} & \multicolumn{3}{|c|}{ Vinyl ester, 0} & \multicolumn{3}{|c|}{ Neat Resin } \\
\hline \multicolumn{15}{|c|}{ Effect of additives and particulate size of additive } \\
\hline \multicolumn{6}{|c|}{ Graphite powder } & & \multicolumn{5}{|c|}{ Chopped carbon fiber } & \multicolumn{3}{|c|}{ Carbon nano-tubes } \\
\hline \multicolumn{4}{|c|}{$10 \mathrm{Wt} \%$} & \multirow{2}{*}{\multicolumn{2}{|c|}{$12.5 \mathrm{Wt} \%$}} & & \multirow{2}{*}{\multicolumn{2}{|c|}{$0.15 \mathrm{Wt} \%$}} & \multirow{2}{*}{\multicolumn{3}{|c|}{$0.4 \mathrm{Wt} \%$}} & \multirow{2}{*}{\multicolumn{3}{|c|}{$0.25 \mathrm{Wt} \%$}} \\
\hline $44 \mu$ & $55 \mu$ & $75 \mu$ & $150 \mu$ & & & & & & & & & & & \\
\hline \multicolumn{4}{|c|}{ Th } & & Th & & \multicolumn{8}{|c|}{ Th } \\
\hline \multicolumn{6}{|c|}{ Vinyl ester } & & \multicolumn{8}{|c|}{ Vinyl ester } \\
\hline
\end{tabular}

Note:

L Longitudinal

Tr Transverse

Th Through the thickness

F Flange

W Web 
The test samples were prepared in the form of two-inch diameter circular discs using compression molding and hand lay-up methods. Ideally all samples for threedimensional measurements should be cut from same block. Since one layer of fabric of density $27 \mathrm{oz} / \mathrm{yd}^{2}$ approximately gives a laminate of thickness $0.04 \%, 100$ layers of fabric would be required to manufacture a three-inch thick block. Technically this poses a great difficulty in manufacturing such a block in terms of proper alignment of fabric and wet out.

Typically, FRP laminate has a thickness of $1 / 8$ " to $1 / 2$ ". A two-inch diameter disc was cut from this type of laminate to measure its thermal conductivity with heat flowing through the thickness direction. In order to prepare samples for the measurements of thermal conductivity along the 0 degree and 90-degree fiber orientation, 5 to 20 layers of laminates need to be joined together with Pliogrip ${ }^{\circledR}$ to arrive at an overall thickness of 2.5 inch. To ensure the quality of test sample and measurement accuracy, CSM was removed from the surface of laminates during sample preparation.

Both the above discussed approaches were used to prepare samples in the present study. As a result, we have successfully prepared a couple of samples that allow for thermal conductivity measurements in transverse, longitudinal, and through the thickness directions.

\subsection{Resin casting with or without additives}

The resins used for this study were vinyl ester, polyester and epoxy. Hetron $922 \mathrm{~L}$ 25 Vinyl ester resin was obtained from Ashland and Derakane 8084 was obtained from Dow chemicals. To prepare vinyl ester neat resin sample, 2\% Methyl Ethyl Ketone Peroxide (MEKP) was used as a catalyst. The epoxy used was Tyfo S Saturant epoxy consisting of components A and B obtained from FYFE Co. LLC. Part A is epoxy resin and part B is hardener. To prepare epoxy neat resin sample, part A and part B were mixed in the proportion of 100:44.5 ratio by weight. For polyester sample, the polyester resin was mixed with 2\% MEKP (catalyst) and 6\% Cobalt Napthanate (promoter). The promoter was mixed in the resin thoroughly before adding the initiator. The reaction between initiator and promoter caused the resin to become gel. Since the reaction between initiator and promoter is very fast, an inhibitor was added to increase the gel 
time. $10 \%$ Hydroquinone in menthol was used as inhibitor. Derakane 8084, polyester, epoxy neat resins were set to cure in 2 inch diameter Teflon molds where as Hetron 922 L 25 vinyl ester was prepared using Resin Transfer Molding (RTM) machine. This sample was cut into 2-inch diameter disc using hole-saw. Neat resin samples of Vinyl ester, polyester and epoxy are shown in Figure 4.1.

To determine the influence of additives on the thermal conductivity, graphite powder GP 55 -B (UCAR Carbon Company, Clarksburg, WV) was added into 8084 vinyl ester resin at two different proportions, i.e. $10 \mathrm{wt} \%$ and $12.5 \mathrm{wt} \%$ respectively. The additive was thoroughly mixed in the resin and molded into 2 inch diameter discs of a thickness approximately $16 \mathrm{~mm}$ using Teflon molds. Carbon nano tubes (CNT) were also used as additives to prepare $0.25 \mathrm{wt} \% \mathrm{CNT} / 8084$ vinyl ester samples for thermal conductivity measurements. Figure 4.2 shows those Derakane 8084 vinyl ester samples with or without additives.

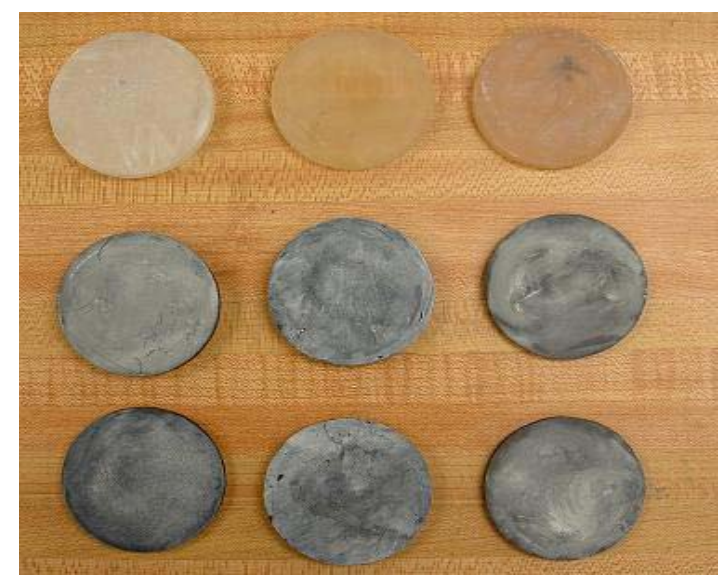

Figure 4.1 Samples of Epoxy, Vinyl ester and Polyester resins on top row; samples with different particulate sizes of graphite powder additive, chopped carbon fiber additives in bottom two rows 


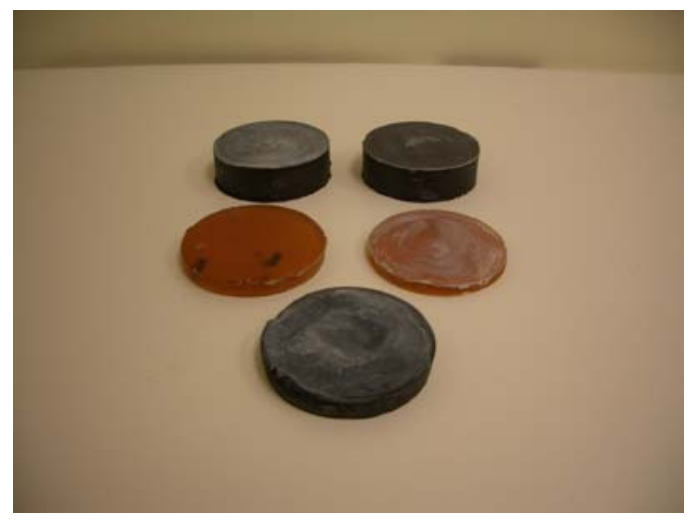

Figure 4.2 Samples of Derakane 8084 vinyl ester resin with or without additives

In addition to these, chopped carbon fiber was also added as additive to prepare samples with $0.15 \mathrm{wt} \%$ and $0.3 \mathrm{wt} \%$ of vinyl ester. To investigate the effect of particulate size of an additive material, 44micron, 55 micron, 75 micron and 150 micron sized graphite powders were used to prepare samples. All these additives were thoroughly dispersed in the resin system using Branson 2510 Sonicator $^{\circledR}$, a machine which uses ultrasound waves for dispersion. All these samples were molded in the same 2-inch diameter Teflon mold. These samples with mold and Sonicator ${ }^{\circledR}$ are shown in Figure 4.3
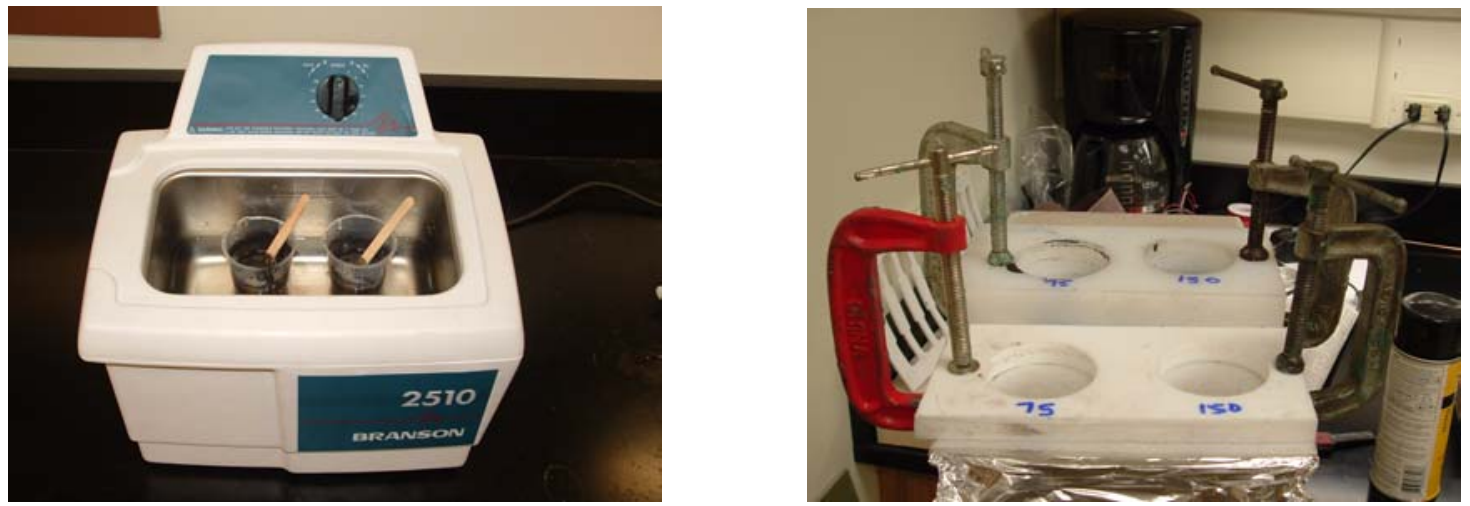

Figure 4.3 Sonicator $^{\circledR}$ and Teflon mold 


\subsection{E-glass/vinyl ester laminates with or without stitching}

5 layers of 24oz 0/90 bi-axial FGI fabric infused with Hetron 922 vinyl ester samples were prepared by using hand-lay up and compression molding procedures at a compressive pressure of 100 psi. The molded sample was cut into 2-inch diameter discs using hole-saw. For stitched samples, 5 layers of 24oz 0/90 bi-axial FGI fabric were stitched together using 4 ply polyester thread with a pitch of $4 \mathrm{~mm}$ and at a spacing of 8 $\mathrm{mm}$ along the thickness and then used to prepare samples along with Hetron 922 vinyl ester resin. To examine the possible effect of surface resin rich layer, samples were also tested after removal of the surface layer. Figure 4.4 shows a group of FRP composite samples tested, including stitched and non-stitched laminate samples.

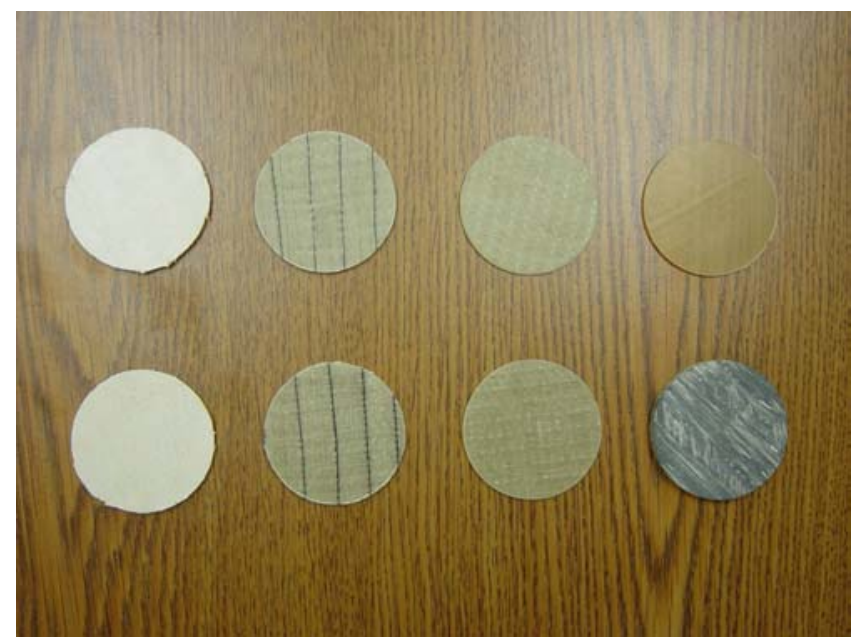

Figure 4.4 Miscellaneous FRP composite samples tested

Left to right: garage door panel, stitched and non-stitched laminate, Neat 922 Vinyl ester, and bridge deck samples.

\subsection{Epoxy based wearing surface}

A wearing surface is used to provide friction enabling easy transit of vehicles and protection for composite bridge decks. The wearing surface consists of fine aggregates or sand bonded together with a polymer resin. A thin layer (about 3/8") of polymer concrete wearing surface is usually used for FRP bridge decks. In this study, a wearing surface made of Transpo T-48 epoxy resin binder was cast using a compact rolling technique and cut into two- inch circular disks. The rough surface of the samples was sanded to arrive at 
acceptable smooth surface level for thermal conductivity measurements. One wearing surface sample is shown in Figure 4.5.

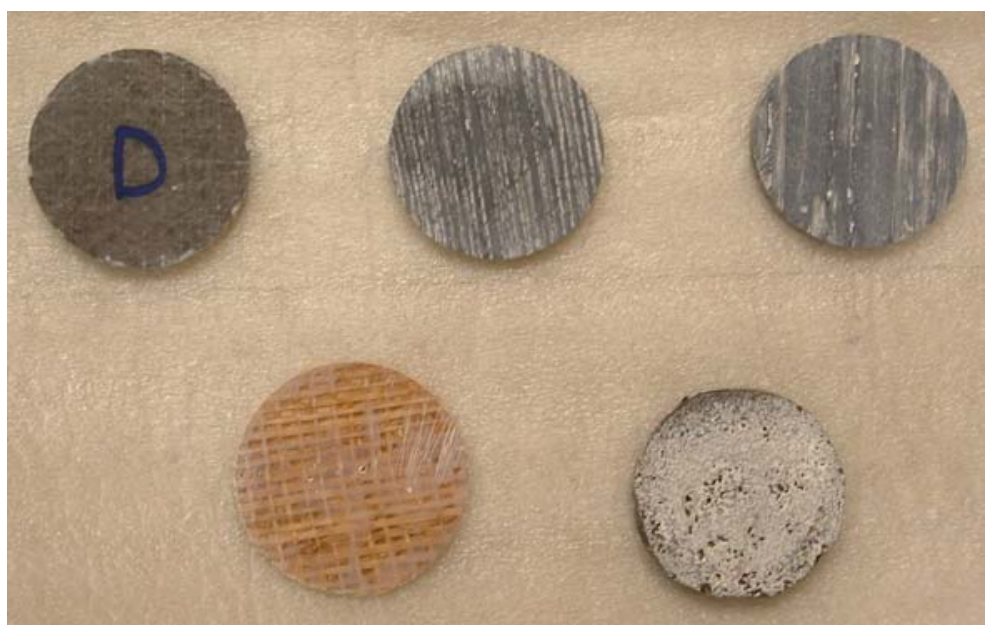

Figure 4.5 Samples of bridge deck, natural fiber, deck with epoxy wearing surface

\subsection{Natural fiber /vinyl ester composites}

In this study, a natural fiber composite material was tested for its thermal conductivity in a limited manner because of its growing importance (Colton 2005). This natural fiber composite plate was made of four layers of natural fiber mat wet out with vinyl ester by hand-lay up process and cut into two-inch diameter disks for thermal conductivity measurement in the thickness direction. A photographic view of the sample is also shown in Figure 4.5.

\subsection{FRP garage door panel}

Samples were cut from a quarter inch thick pultruded FRP garage door panel. This panel was made of unidirectional rovings impregnated with polyester resin. Both samples (with and without removal of surface resin rich layer) were tested, as shown in Figure 4.4.

\subsection{E-Glass Vinyl ester composite block}

An E-glass /vinyl ester composite block was prepared and used as a control sample for thermal conductivity measurements. This block was prepared in the shape of a cube of 2.5 inch each side. The cube was made by joining two smaller plates using a very 
thin layer of adhesive (Pliogrip ${ }^{\circledR}$ ), each plate consisting of 55 layers of 24 oz E- glass bi axial FGI fabric. Sheets of about 0.2 inch thickness were cut from this cube in longitudinal, transverse and through the thickness directions. Discs of 2 inch diameter were cut from those sheets using a hole-saw. The specimens along with the remaining block were shown in Figure 4.6. In this case, the amount of adhesive (Pliogrip ${ }^{\circledR}$ ) was minimized for joining two parts into a block in order to avoid its possible effect on the resulting thermal conductivity values.

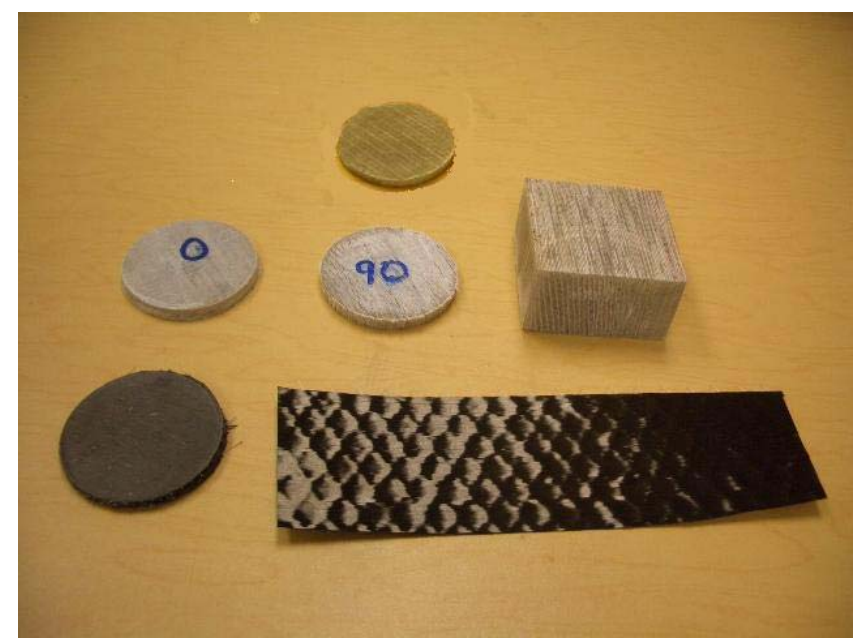

Figure 4.6 E-glass/vinyl ester block and three dimensional samples, carbon tow and carbon/vinyl ester sheet sample

\subsection{Carbon fiber/ vinyl ester composite sheet and block}

Both carbon fiber/vinyl ester composite sheet and composite block were made for thermal conductivity measurements. A tow of carbon fiber was cut into 5-inch squares and 6 layers of these squares were used for sheet preparation. The carbon fiber /vinyl ester composite sheet was hand-laid up and then compressed. The sheet was cut into a circular disc using a hole-saw. The carbon fiber tow and resulting specimen are also shown in Figure 4.6.

A carbon/vinyl ester composite block was prepared to generate all test specimens in three directions, i.e. through the thickness, longitudinal and transverse directions. The block was made in the shape of cuboids of dimensions 6"x6"x3", consisting of nearly 260 layers of carbon fiber tow sheets of density $0.056 \mathrm{lbs} / \mathrm{in}^{3}$. The tow sheet (tape) was made of unidirectional fiber $\left(0^{0}\right)$ and the fibers were supported on a glass fiber scrim. A 
rectangular wooden mold was used to hold those carbon fiber tow sheets. Hence, the tow sheets were hand-laid, wetted with vinyl ester and then compression molded into the block. Three plates of a quarter inch in thickness were cut from the block from each direction and two-inch diameter circular disks were cut from each plate using a 2-inch diameter carbide or diamond tipped hole-saw. Thus, six disks for each direction were prepared giving a total of 18 specimens. Three typical specimens along with the block are shown in Figure 4.7.

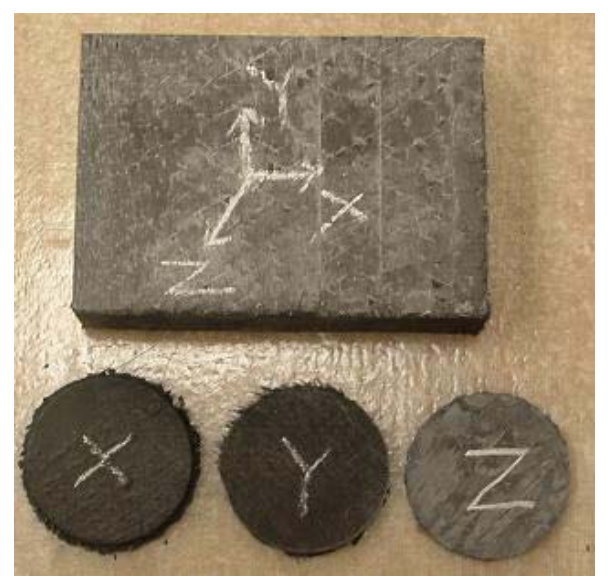

Figure 4.7 Carbon fiber /vinyl ester composite block and specimens along fiber direction (marked $\mathrm{X}$ ), in transverse direction (Y) and through the thickness direction $(Z)$

To verify the effect of fiber volume fraction on thermal conductivity of composites, another carbon/vinyl ester composite block with around 300 layers was prepared. In order to squeeze out the excess resin a compressive force of 410 psi was applied using compression molding machine. This method resulted in higher volume fraction and good alignment of fabric through out the composite.

\subsection{Prodeck 4 and Prodeck 8 bridge decks}

Prodeck 4 is 4 inches in depth, while Prodeck 8 is 8 inches in depth. Both bridge decks were developed by CFC-WVU researchers and mass-produced through pultrusion by BRP Inc. These two types of FRP bridge decks were tested extensively for their thermal conductivities.

Through-the-thickness: Both bridge deck samples were tested for their thermal conductivity through the thickness direction. For example, half inch thick bridge deck panel samples from Prodeck 8 with a fabric configuration of 8 layers of 0/+-45 tri-axial 
fabric TV4000 and 60 glass fiber roving impregnated with vinyl ester were tested with the surface CSM removed when mill-grinding to the required thickness. One of these samples is also shown in Figure 4.2. However, a 4" bridge deck sample was tested for its thermal conductivity through the thickness direction without removing surface CSM in order to reflect the situation similar to field applications. This sample is also shown in Figure 4.4.

3-D Evaluation: The thermal conductivity measurements in the longitudinal direction (i.e. parallel to 0 degree fiber orientation) and transverse direction (i.e. parallel to 90 degree fiber orientation) as well as through the thickness direction were carried out using 8 inch depth FRP bridge deck. A section of the bridge deck flange panel was cut across the width into required number of small pieces with an optimum dimension (about 0.7 inch in width). Then these little pieces were flipped by 90 degrees so as to get the 0 degree fibers in vertical direction and were glued together using Pliogrip, an adhesive used to join FRP modules. The glued plate was then mill-grinded to a required thickness of about $0.18 \mathrm{inch}$. The plate was cut using a hole-saw into two-inch diameter disks and used for thermal conductivity measurement along the longitudinal direction. Similarly, specimens were prepared for thermal conductivity measurement along the transverse direction by cutting the deck panel into little pieces across the length.

Flange and Web Sections: Samples cut from different portions of the bridge decks were tested along the thickness direction for their thermal conductivity properties. The samples were prepared from both the web section and flange section of the four-inch and eight-inch FRP bridge decks. In order to be accommodated with the heat flow meter model Unitherm 2022, each entire section was ripped across the thickness into three equal pieces, i.e. top, middle and bottom parts from either web or flange of both 4-inch and 8-inch decks. The thermal conductivity was determined for each part and then compared to the value obtained from testing the entire section. Figures 4.8 and 4.9 show the samples from the 4 inch and 8 inch decks respectively. 


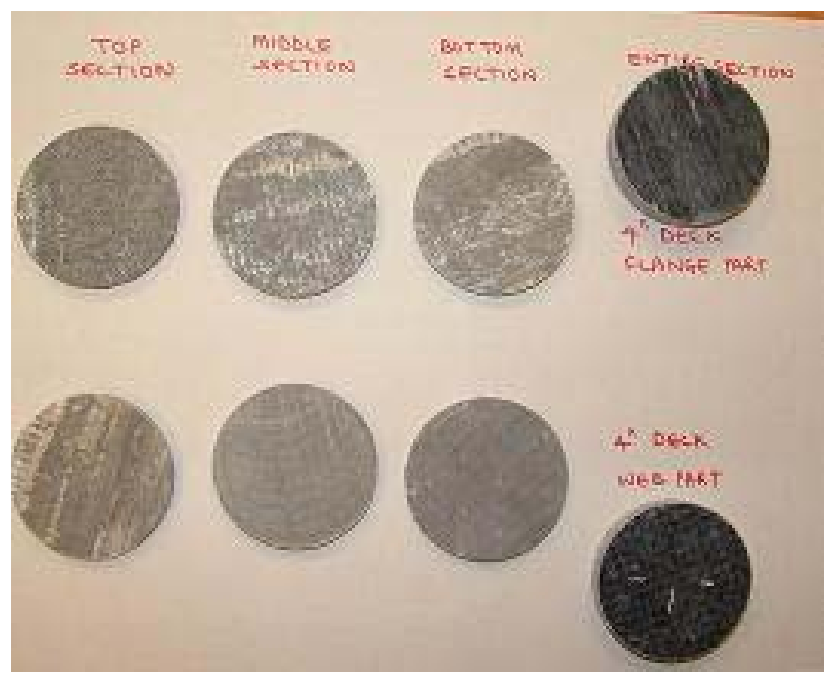

Figure 4.8 Samples prepared from web and flange sections of Prodeck 4

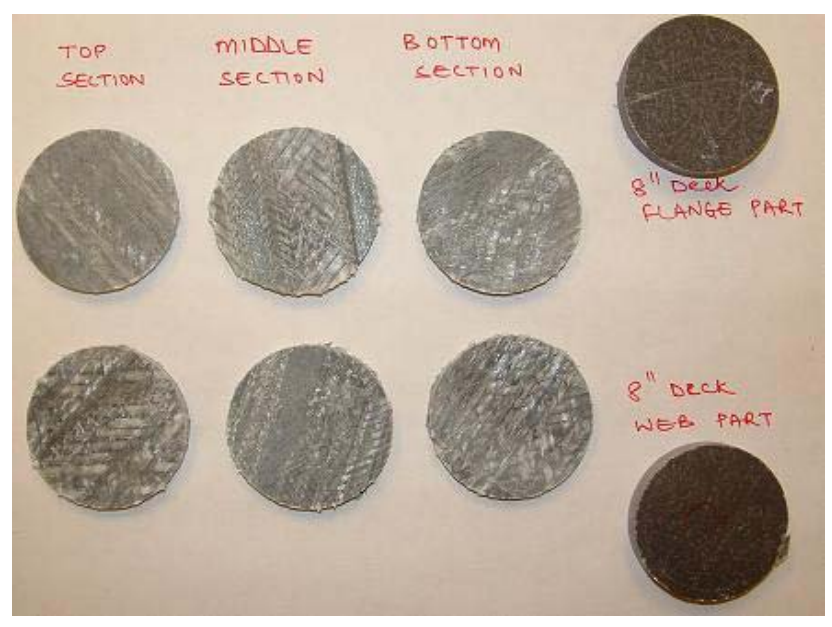

Figure 4.9 Samples prepared from web and flange sections of Prodeck 8 


\section{CHAPTER 5}

\section{EXPERIMENTAL RESULTS AND DISCUSSION}

\subsection{Introduction}

The objective of the experimental investigation is to determine longitudinal, transverse and through-the-thickness thermal conductivity of composite materials with known material compositions and fiber configurations. In addition the thermal conductivity variation was examined as a function of fiber type, fiber volume fraction, and other parameters, such as additives and fillers. This chapter presents the results and discusses thermal conductivity variations as a function of composite material parameters.

\subsection{Neat resin castings and resin castings with additives}

The thermal conductivity of a composite depends on many parameters including 1) Direction of fiber; 2) Specific gravity of fiber; 3) Moisture content; 4) Distribution of moisture; 5) Voids or cross fibers; 6) Resin type. The parameters of major influence on thermal conductivity are fiber volume percentage and conductivity properties of both resin and fiber. In this present study, thermal conductivities of different resins like Hetron 922 L 25 vinyl ester, Derakane 8084 vinyl ester, polyester, and epoxy were determined and the results are in agreement with the literature (Callister, 1990). One sample with Hetron 922 L 25 vinyl ester resin samples was prepared using RTM and other neat resin samples were prepared using a 2 inch diameter Teflon mold. The results are listed in Table 5.1 and graphically presented in Figure 5.1.

Additives like graphite powder, carbon nano-tubes and chopped carbon fibers were directly mixed with the resin and the effect of addition of these additives on thermal conductivity was determined. Different samples with $10 \mathrm{wt} \%, 12.5 \mathrm{wt} \%$ of graphite powder, $0.25 \mathrm{wt} \%$ of carbon nano-tubes, $0.15 \mathrm{wt} \%$ and $0.3 \mathrm{wt} \%$ of chopped carbon fibers were mixed in the resin for testing and results are listed in Table 5.2 and graphically plotted in Figures 5.2 and 5.3. In addition to the above tests, the effect of particulate size of additives in Hetron 922 L 25 vinyl ester resin was investigated. Samples with 10-wt \% 
graphite additive with vinyl ester were prepared with particulate sizes $44 \mu, 55 \mu, 75 \mu$ and $150 \mu$. The results were listed in Table 5.2.

Table 5.1 Thermal conductivity values of different resins

\begin{tabular}{|c|c|c|c|c|}
\hline \multirow[b]{2}{*}{ Sample } & \multirow{2}{*}{$\begin{array}{c}\text { Thickness } \\
\text { mm } \\
\text { (inch) }\end{array}$} & \multicolumn{3}{|c|}{ Thermal conductivity, W/m K } \\
\hline & & $\begin{array}{l}\text { Segment } 1 \\
\text { at } 140^{0} \mathrm{~F}\left(60^{0} \mathrm{C}\right)\end{array}$ & $\begin{array}{c}\text { Segment } 2 \\
\text { at } 140^{0} \mathrm{~F}\left(80^{0} \mathrm{C}\right)\end{array}$ & $\begin{array}{c}\text { Segment } 3 \\
\text { at } 212^{0} \mathrm{~F}\left(100^{0} \mathrm{C}\right)\end{array}$ \\
\hline $\begin{array}{l}\text { Neat resin Hetron } \\
922 \text { Vinyl ester } \\
\text { (RTM) }\end{array}$ & $\begin{array}{c}2.006 \\
(0.079)\end{array}$ & 0.188 & 0.197 & 0.201 \\
\hline \multirow{3}{*}{$\begin{array}{l}\text { Neat resin Hetron } \\
922 \text { Vinyl ester }\end{array}$} & $\begin{array}{c}7.106 \\
(0.2797)\end{array}$ & 0.211 & 0.218 & 0.221 \\
\hline & $\begin{array}{c}9.15 \\
(0.3602)\end{array}$ & 0.215 & 0.230 & 0.235 \\
\hline & Average & 0.213 & 0.224 & 0.228 \\
\hline $\begin{array}{l}\text { Derakane } 8084 \text { neat } \\
\text { resin }\end{array}$ & $\begin{array}{c}4.594 \\
(0.18085)\end{array}$ & 0.178 & 0.184 & 0.192 \\
\hline \multirow{3}{*}{ Neat Polyester resin } & $\begin{array}{c}7.569 \\
(0.298) \\
\end{array}$ & 0.214 & 0.219 & 0.224 \\
\hline & $\begin{array}{c}6.769 \\
(0.2665) \\
\end{array}$ & 0.204 & 0.216 & 0.219 \\
\hline & Average & 0.209 & 0.218 & 0.222 \\
\hline Neat Epoxy & $\begin{array}{c}8.052 \\
(0.317)\end{array}$ & 0.229 & 0.249 & 0.256 \\
\hline
\end{tabular}

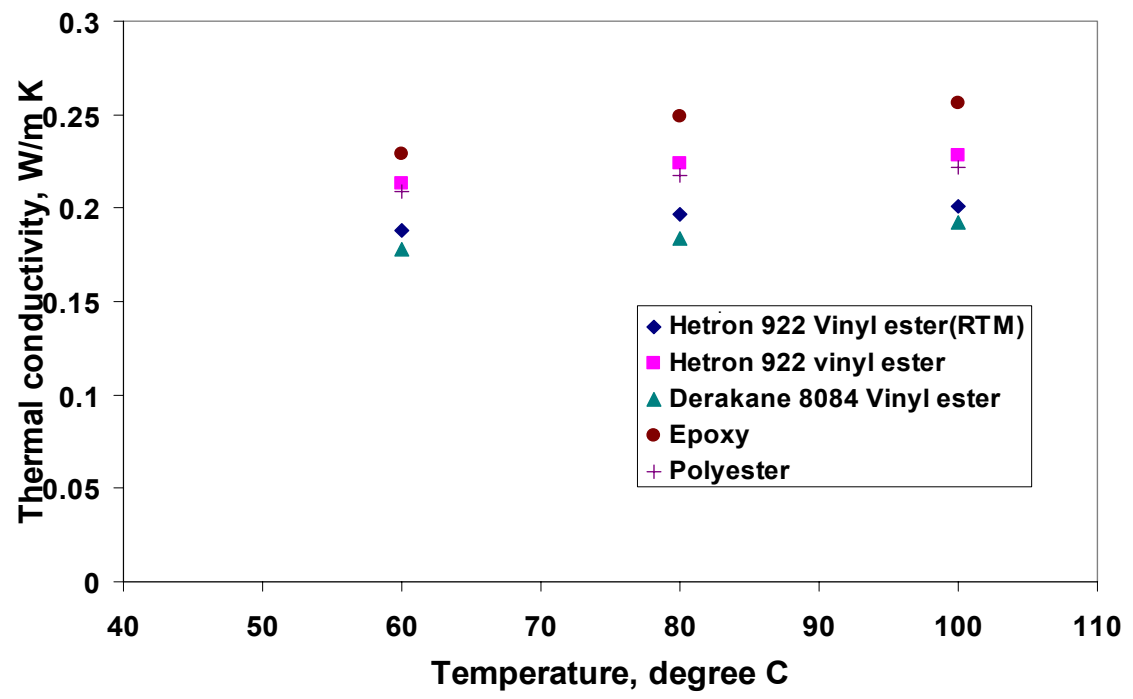

Figure 5.1 Thermal conductivity variations of different resins 
Table 5.2 Thermal conductivity values of vinyl ester resins with different additives and particulate size of additive

\begin{tabular}{|c|c|c|c|c|}
\hline \multirow[b]{2}{*}{ Sample } & \multirow{2}{*}{$\begin{array}{l}\text { Thickness } \\
\text { mm } \\
\text { (inch) }\end{array}$} & \multicolumn{3}{|c|}{ Thermal conductivity, W/m K } \\
\hline & & $\begin{array}{l}\text { Segment } 1 \\
\text { at } 140^{0} \mathrm{~F}\left(60^{0} \mathrm{C}\right)\end{array}$ & $\begin{array}{c}\text { Segment } 2 \\
\text { at } 140^{0} \mathrm{~F}\left(80^{0} \mathrm{C}\right)\end{array}$ & $\begin{array}{c}\text { Segment } 3 \\
\text { at } 212^{0} \mathrm{~F}\left(100^{0} \mathrm{C}\right)\end{array}$ \\
\hline $\begin{array}{l}\text { Derakane } 8084 \text { neat } \\
\text { resin }\end{array}$ & $\begin{array}{c}4.594 \\
(0.18085)\end{array}$ & 0.178 & 0.184 & 0.192 \\
\hline $\begin{array}{l}10 \mathrm{wt} \% \text { graphite } \\
\text { powder } / 8084\end{array}$ & $\begin{array}{c}16.021 \\
(0.6307)\end{array}$ & 0.358 & 0.368 & 0.361 \\
\hline $\begin{array}{l}12.5 \mathrm{wt} \% \text { graphite } \\
\text { powder } / 8084\end{array}$ & $\begin{array}{c}16.186 \\
(0.6372) \\
\end{array}$ & 0.496 & 0.536 & 0.515 \\
\hline $\begin{array}{l}0.25 \mathrm{wt} \% \text { carbon nano } \\
\text { tubes } / 8084\end{array}$ & $\begin{array}{c}8.528 \\
(0.3357)\end{array}$ & 0.239 & 0.198 & 0.192 \\
\hline \multirow{3}{*}{$\begin{array}{l}0.15 \mathrm{wt} \% \text { chopped } \\
\text { carbon fiber/Hetron } \\
\text { Vinyl ester resin }\end{array}$} & $\begin{array}{c}6.985 \\
(0.275) \\
\end{array}$ & 0.225 & 0.226 & 0.229 \\
\hline & $\begin{array}{c}5.709 \\
(0.2247)\end{array}$ & 0.209 & 0.214 & 0.224 \\
\hline & Average & 0.217 & 0.220 & 0.227 \\
\hline \multirow{3}{*}{$\begin{array}{l}0.3 \mathrm{wt} \% \text { chopped } \\
\text { carbon fiber/ Hetron } \\
\text { Vinyl ester resin }\end{array}$} & $\begin{array}{c}6.896 \\
(0.2715)\end{array}$ & 0.224 & 0.228 & 0.236 \\
\hline & $\begin{array}{c}7.7128 \\
(0.3042)\end{array}$ & 0.224 & 0.231 & 0.243 \\
\hline & Average & 0.224 & 0.230 & 0.234 \\
\hline \multirow{3}{*}{$\begin{array}{l}44 \mu \text { size } 10 w t \% \\
\text { graphite } \\
\text { powder/Hetron Vinyl } \\
\text { ester resin }\end{array}$} & $\begin{array}{c}10.528 \\
(0.4145)\end{array}$ & 0.414 & 0.432 & 0.428 \\
\hline & $\begin{array}{c}12.605 \\
(0.4962)\end{array}$ & 0.394 & 0.408 & 0.42 \\
\hline & Average & 0.404 & 0.420 & 0.424 \\
\hline \multirow{3}{*}{$\begin{array}{l}55 \mu \text { size } 10 \mathrm{wt} \% \\
\text { graphite } \\
\text { powder/Hetron Vinyl } \\
\text { ester resin }\end{array}$} & $\begin{array}{c}9.646 \\
(0.3797) \\
\end{array}$ & 0.423 & 0.438 & 0.448 \\
\hline & $\begin{array}{c}11.911 \\
(0.4689) \\
\end{array}$ & 0.384 & 0.398 & 0.397 \\
\hline & Average & 0.404 & 0.418 & 0.423 \\
\hline \multirow{3}{*}{$\begin{array}{l}75 \mu \text { size } 10 \mathrm{wt} \% \\
\text { graphite } \\
\text { powder/Hetron Vinyl } \\
\text { ester resin }\end{array}$} & $\begin{array}{c}7.683 \\
(0.3025) \\
\end{array}$ & 0.351 & 0.362 & 0.374 \\
\hline & $\begin{array}{c}4.807 \\
(0.1892) \\
\end{array}$ & 0.341 & 0.366 & 0.38 \\
\hline & Average & 0.346 & 0.364 & 0.377 \\
\hline \multirow{3}{*}{$\begin{array}{l}150 \mu \text { size } 10 \mathrm{wt} \% \\
\text { graphite } \\
\text { powder/Hetron Vinyl } \\
\text { ester resin }\end{array}$} & $\begin{array}{c}9.106 \\
(0.3585) \\
\end{array}$ & 0.352 & 0.354 & 0.358 \\
\hline & $\begin{array}{c}4.54 \\
(0.1787) \\
\end{array}$ & 0.318 & 0.338 & 0.355 \\
\hline & Average & 0.335 & 0.346 & 0.357 \\
\hline
\end{tabular}


The results show that the thermal conductivity values of vinyl ester, polyester, and epoxy have nearly the same values. As the RTM made Hetron 922 vinyl ester sample has little air voids, it is showing lower thermal conductivity than the one made in Teflon mold. Addition of graphite powder significantly increases the thermal conductivity. For example, $10 \mathrm{wt} \%$ and $12.5 \mathrm{wt} \%$ respectively result in $80 \%$ and $170 \%$ increase in thermal conductivity over neat resin for temperatures ranging from $60-100^{\circ} \mathrm{C}$. However, for carbon nano-tubes with vinyl ester 8084 samples, slight increase in thermal conductivity is noted at the temperature segment of $60^{\circ} \mathrm{C}$ when compared to the neat vinyl ester resin; but the thermal conductivity almost remains unchanged at the temperature range of $80^{\circ} \mathrm{C}$ to $100^{\circ} \mathrm{C}$. This could have happened because addition of carbon nano-tubes makes the sample brittle and hairline cracks were formed in the sample under heat and pressure. These cracks create air voids thus reducing the heat capacity and corresponding thermal conductivity. These results are tabulated in Table 5.2 and plotted in Figure 5.2.

Vinyl ester resin samples with $10 \mathrm{wt} \%$ of graphite powder were tested for different graphite particulate sizes $44 \mu, 55 \mu, 75 \mu$ and $150 \mu$; the test results are given in Table 5.2. Figure 5.3 shows the graphical representation of variation in thermal conductivity values for varying particle size for same weight fraction of the additive. Two samples of each kind were tested for replication and the data were repetitive. The addition of finer grade additives increases the thermal conductivity of a sample than that of coarse grade additives. The reason is that the finer particles tend to get in contact with more resin molecules i.e. higher surface area in case of finer particles than the coarser particles in the resin.

Addition of chopped carbon fiber at $0.15 \mathrm{wt} \%$ and $0.3 \mathrm{wt} \%$ increased the thermal conductivity by nearly $12.5 \%$ and $19 \%$ respectively, but further increase in $\mathrm{wt} \%$ (say after $0.3 \mathrm{wt} \%$ ) of this additive increases the viscosity of the resin. As a result, sample preparation to a required shape with this resin system becomes much more difficult and also there is a possibility of getting micro cracks in the sample. 


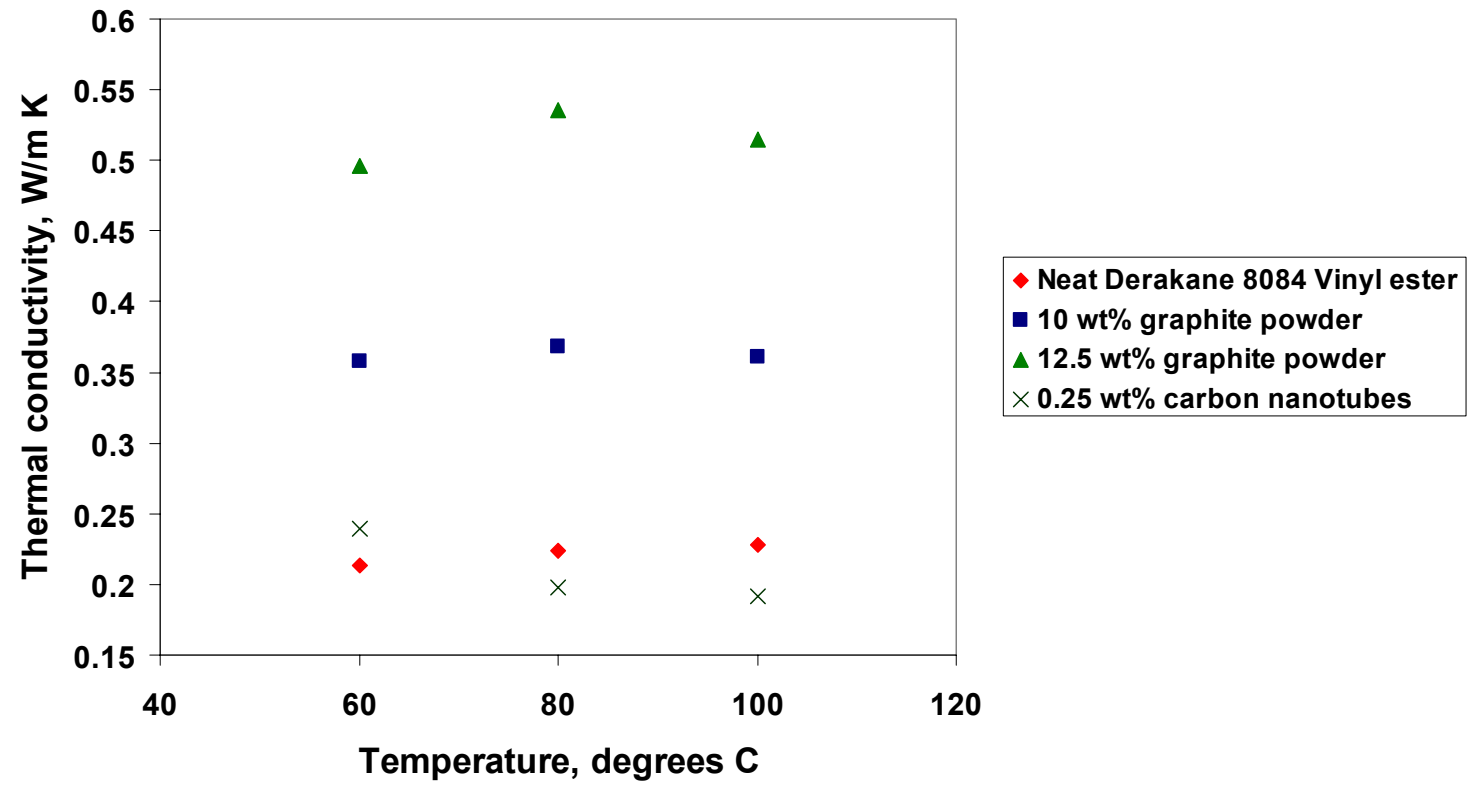

Figure 5.2 Thermal conductivity variations with graphite additives, with carbon nano-tubes in Derakane 8084 vinyl ester resin

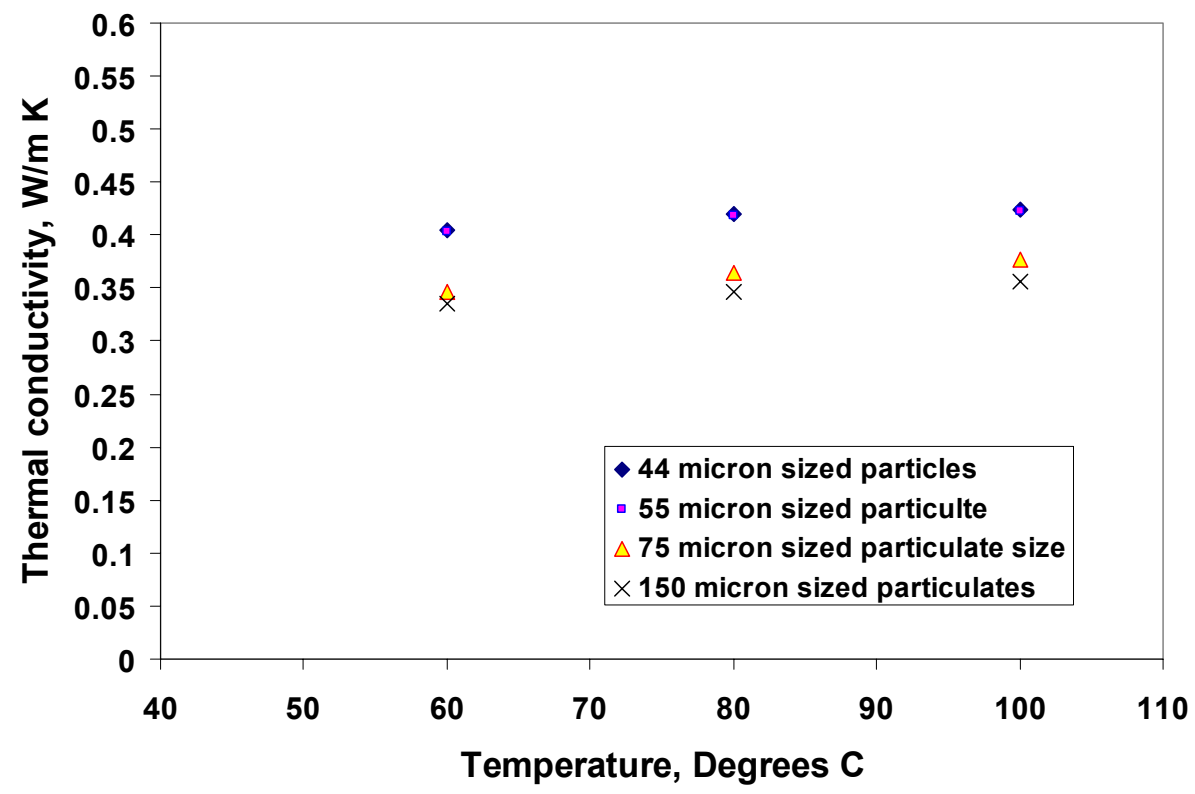

Figure 5.3 Thermal conductivity variations with change in particulate size of graphite additives in Hetron 922 vinyl ester resin 


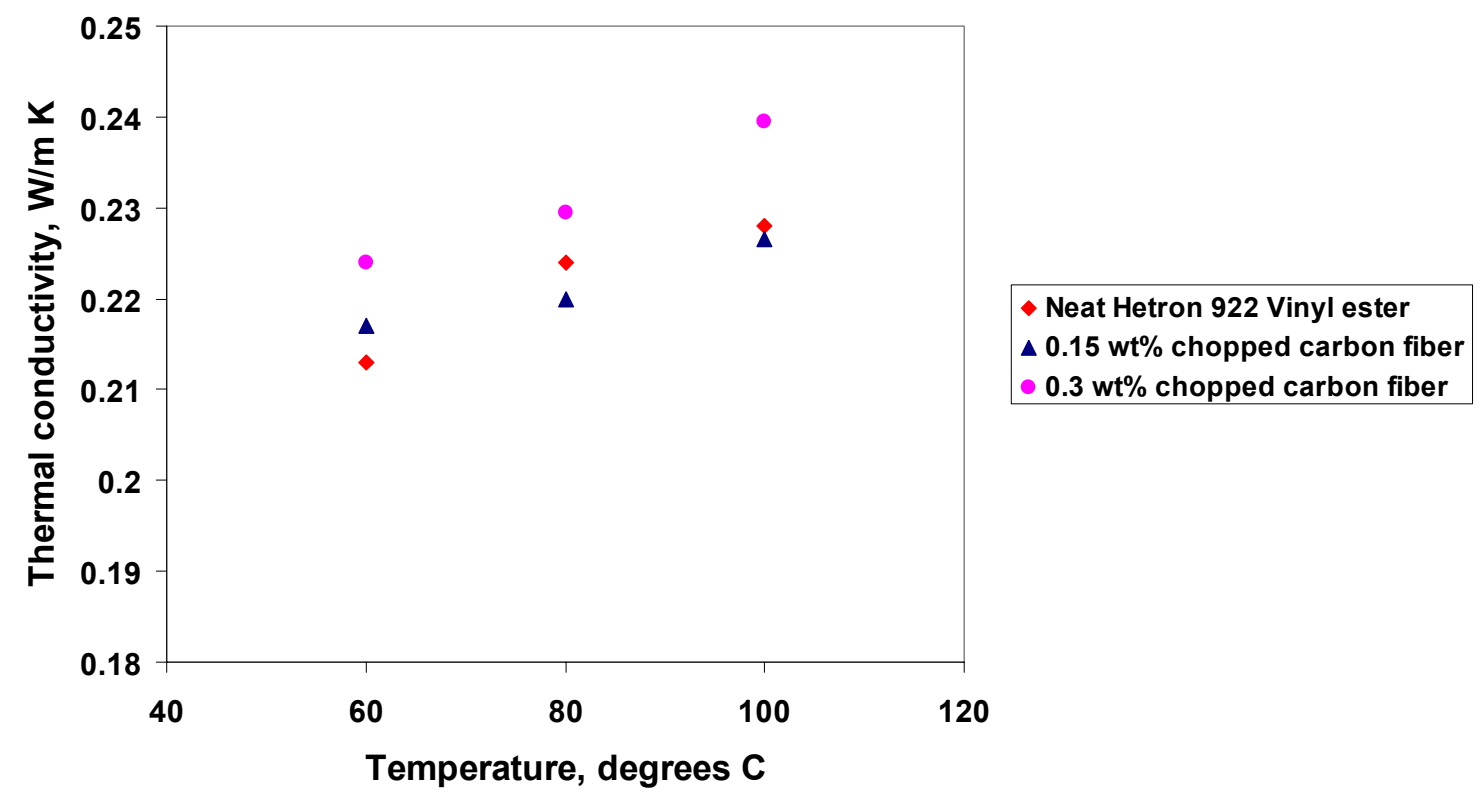

Figure 5.4 Thermal conductivity variations with chopped carbon fiber additives in Hetron $922 \mathrm{~L}$ vinyl ester resin

\subsection{E-glass /vinyl ester laminates with or without stitching}

Thermal conductivity measurements of E-glass/Vinyl ester samples with third dimensional reinforcement (i.e. introducing fiber along the thickness direction by stitching the fabric) and without third dimensional reinforcement are reported in Table 5.3. Thermal conductivity data for these samples were obtained by testing in through-thethickness direction. For glass/vinyl ester composites, manufacturing method has little effect on thermal conductivity. Experimental results show that non- stitched samples have higher thermal conductivity than stitched samples. The potential cause for this variation in thermal conductivity might be due to air voids. Two potential reasons are suggested for formation of air voids: 1) stitching closely packs the fabric layers, leaving small air pockets between the layers, and applied resin might not seep through the air gaps fully, these air pockets hinder full conductivity; and 2) stitching forms holes and may even form a thin interfacial gap between the thread and resin due to inadequate interfacial compatibility acting like air void and in turn reducing the thermal conductivity. These factors potentially change thermal conductivity by around $\pm 0.05 \mathrm{~W} / \mathrm{m}-\mathrm{K}$. The removal of the top resin rich layer of the samples improved thermal conduction as it allows the fabric layers of the sample to get in direct contact with the heating plates of the testing 
facility. For all samples thermal conductivity increases slightly with test increased temperature.

Table 5.3 Thermal conductivity of E-glass /vinyl ester laminates

\begin{tabular}{|c|c|c|c|c|c|}
\hline \multirow[b]{2}{*}{ Sample } & \multirow{2}{*}{$\begin{array}{l}\text { Manufacturing } \\
\text { method/ fabric } \\
\text { configuration }\end{array}$} & \multirow[b]{2}{*}{$\begin{array}{c}\text { Thickness, } \\
\text { mm }\end{array}$} & \multicolumn{3}{|c|}{ Thermal conductivity, $\mathrm{W} / \mathrm{m} \mathrm{K}$} \\
\hline & & & $\begin{array}{c}\text { Segment } 1 \\
\text { at } 140^{\circ} \mathrm{F} \\
\left(60^{\circ} \mathrm{C}\right)\end{array}$ & $\begin{array}{c}\text { Segment } 2 \\
\text { at } 176^{\circ} \mathrm{F} \\
\left(80^{\circ} \mathrm{C}\right)\end{array}$ & $\begin{array}{c}\text { Segment } 3 \\
\text { at } 212^{0} \mathrm{~F} \\
\left(100^{\circ} \mathrm{C}\right)\end{array}$ \\
\hline $\begin{array}{l}\text { Non stitched } \\
\text { laminate, as- } \\
\text { molded }\end{array}$ & $\begin{array}{l}\text { Compression/ } \\
0 / 90 \text { fabric }\end{array}$ & 2.7432 & 0.372 & 0.390 & 0.413 \\
\hline $\begin{array}{l}\text { Non stitched } \\
\text { laminate with } \\
\text { surface removal }\end{array}$ & $\begin{array}{l}\text { Compression/ } \\
0 / 90 \text { fabric }\end{array}$ & 2.4892 & 0.386 & 0.406 & 0.421 \\
\hline $\begin{array}{l}\text { Stitched } \\
\text { laminate, as- } \\
\text { molded }\end{array}$ & $\begin{array}{l}\text { Compression/ } \\
0 / 90 \text { fabric }\end{array}$ & 2.6670 & 0.302 & 0.336 & 0.378 \\
\hline $\begin{array}{l}\text { Stitched laminate } \\
\text { with surface } \\
\text { removal }\end{array}$ & $\begin{array}{l}\text { Compression/ } \\
0 / 90 \text { fabric }\end{array}$ & 2.4892 & 0.328 & 0.347 & 0.369 \\
\hline
\end{tabular}

\subsection{Miscellaneous composite samples}

Thermal conductivities were determined for composite samples including epoxywearing surface, natural fiber/vinyl ester composite, FRP garage door panel, urethane/ glass fiber pultruded sample, carbon/vinyl ester pultruded samples. These results are tabulated in Table 5.4.

The epoxy-wearing surface facilitates better heat conduction at the top surface of FRP bridge deck. The surfaces of the epoxy-wearing surface samples are coated with a thin layer of sand aggregate and that sand layer is responsible for increase in heat conductivity. As a result, epoxy-wearing surface showed nearly twice the thermal conductivity of the FRP deck. This information is also needed to promote the field application of infrared thermography as a NDE tool leading for better quantitative interpretation of the results. 
The results indicate that natural fiber composites have an extremely low thermal conductivity, much lower than neat vinyl ester, demonstrating excellent thermal insulation characteristics..

Urethane pultruded panels are showing more promising characteristics like fire retardance compared to other economically available pultruded products. A sample of a pultruded urethane/ glass fiber composite from BRP Inc. was tested and the result represents the high thermal conductivity of urethane compared to vinyl ester.

A carbon/vinyl ester unidirectional pultruded sample from Creative Pultrusions Inc. was also tested to check the effect of manufacturing method on thermal conductivity across the thickness of the sample. It shows that the pultruded sample is more conductive than hand laid /compression molded samples. This might be because of pultrusion process where fiber being straight, well aligned and the additives in the resin (data not available) etc. Furthermore pultrusion results in better fiber packing than hand lay-up, which attributes to higher conductivity.

Table 5.4 Thermal conductivity of miscellaneous composites

\begin{tabular}{|c|c|c|c|c|c|}
\hline \multirow[b]{2}{*}{ Sample } & \multirow[b]{2}{*}{$\begin{array}{c}\text { Thickness } \\
\text { mm }\end{array}$} & \multirow[b]{2}{*}{$\begin{array}{c}\text { Sample } \\
\text { information }\end{array}$} & \multicolumn{3}{|c|}{ Thermal conductivity, W/m K } \\
\hline & & & $\begin{array}{c}\text { Segment } 1 \\
\text { at } 140^{\circ} \mathrm{F} \\
\left(60^{\circ} \mathrm{C}\right)\end{array}$ & $\begin{array}{c}\text { Segment } 2 \\
\text { at } 176^{0} \mathrm{~F} \\
\left(80^{\circ} \mathrm{C}\right)\end{array}$ & $\begin{array}{c}\text { Segment } 3 \\
\text { at } 212^{0} \mathrm{~F} \\
\left(100^{\circ} \mathrm{C}\right)\end{array}$ \\
\hline $\begin{array}{l}\text { Epoxy based } \\
\text { wearing surface }\end{array}$ & 5.6388 & $\begin{array}{l}\mathrm{T}-48 \text { epoxy } \\
\text { resin }\end{array}$ & 0.630 & 0.689 & 0.737 \\
\hline $\begin{array}{l}\text { Natural fiber } \\
\text { composite }\end{array}$ & 2.3114 & $\begin{array}{c}\text { Compression } \\
\text { natural fiber } \\
\text { mat }\end{array}$ & 0.123 & 0.128 & 0.136 \\
\hline $\begin{array}{l}\text { FRP door panel, } \\
\text { as-pultruded }\end{array}$ & 2.9464 & $\begin{array}{l}\text { Pultrusion } \\
\text { uniroving }\end{array}$ & 0.331 & 0.356 & 0.373 \\
\hline $\begin{array}{l}\text { Pultruded } \\
\text { Carbon sample }\end{array}$ & $\begin{array}{c}4.75 \\
(0.187)\end{array}$ & $\begin{array}{l}\text { Pultrusion } \\
\text { uniroving }\end{array}$ & 0.41 & 0.441 & 0.485 \\
\hline \multirow{3}{*}{$\begin{array}{l}\text { Pultruded } \\
\text { Urethane sample }\end{array}$} & $\begin{array}{c}6.337 \\
(0.2495) \\
\end{array}$ & \multirow{3}{*}{$\begin{array}{l}\text { Pultrusion } \\
\text { Multi axial } \\
\text { glass fiber }\end{array}$} & 0.392 & 0.417 & 0.442 \\
\hline & $\begin{array}{c}6.337 \\
(0.2495)\end{array}$ & & 0.392 & 0.420 & 0.446 \\
\hline & Average & & 0.392 & 0.419 & 0.444 \\
\hline
\end{tabular}




\subsection{E-glass/vinyl ester composite block}

The thermal conductivity values of E-glass/vinyl ester composite blocks in longitudinal, transverse and through-the-thickness directions are listed in Table 5.5. It is observed that the thermal conductivity in through-the-thickness direction is higher than that in the transverse direction, which in turn is higher than the conductivity in longitudinal direction. The conductivity value is supposed to be higher in longitudinal direction. However, in this case, bi-axial fabric might have led to this anomaly. Further more, the sample preparation also influences the results. After cutting the sample in 0 and 90 directions the fiber would be in the direction of heat flow and these fibers form a corrugated shape on the top and bottom surfaces. According to the sample requirements of the test facility, these surfaces are supposed to be smooth with a tolerance of \pm 0.005 inch, which was difficult to achieve with the available resources. However, the thermal conductivity value of the E-glass/vinyl ester block showed no significant change with respect to the direction of fiber. The fiber volume fraction for this block was determined as $49.8 \%$. The low thermal conductivity of balanced biaxial E-glass fabric in 0 and 90 directions (i.e. in horizontal plane) resulted in heat conduction to be nearly uniform in both longitudinal and transverse directions. 
Table 5.5 Thermal conductivities of E-glass/vinyl ester composite block samples

\begin{tabular}{|c|c|c|c|c|}
\hline \multirow[b]{2}{*}{ Heat Flow Direction } & \multirow[b]{2}{*}{$\begin{array}{c}\text { Thickness } \\
\text { mm } \\
\text { (inch) }\end{array}$} & \multicolumn{3}{|c|}{ Thermal conductivity, W/m K } \\
\hline & & $\begin{array}{c}\text { Segment } \\
1 \\
\text { at } 140^{\circ} \mathrm{F} \\
\left(60^{\circ} \mathrm{C}\right)\end{array}$ & $\begin{array}{c}\text { Segment } \\
2 \\
\text { at } 140^{\circ} \mathrm{F} \\
\left(80^{\circ} \mathrm{C}\right)\end{array}$ & $\begin{array}{c}\text { Segment } 3 \\
\text { at } 212^{0} \mathrm{~F} \\
\left(100^{\circ} \mathrm{C}\right)\end{array}$ \\
\hline Through the thickness & $\begin{array}{c}5.023 \\
(0.1977)\end{array}$ & 0.322 & 0.343 & 0.353 \\
\hline \multirow{4}{*}{$\begin{array}{l}\text { Transverse } \\
(\perp 0 \text { fiber) }\end{array}$} & $\begin{array}{c}5.855 \\
(0.2305)\end{array}$ & 0.256 & 0.280 & 0.319 \\
\hline & $\begin{array}{c}5.467 \\
(0.2152)\end{array}$ & 0.307 & 0.326 & 0.348 \\
\hline & $\begin{array}{c}5.81 \\
(0.2287) \\
\end{array}$ & 0.276 & 0.292 & 0.323 \\
\hline & Average & 0.280 & 0.299 & 0.330 \\
\hline \multirow{4}{*}{$\begin{array}{l}\text { Longitudinal } \\
\text { (// } 0 \text { fiber) }\end{array}$} & $\begin{array}{c}5.156 \\
(0.203)\end{array}$ & 0.255 & 0.281 & 0.310 \\
\hline & $\begin{array}{c}5.512 \\
(0.217)\end{array}$ & 0.235 & 0.256 & 0.302 \\
\hline & $\begin{array}{c}5.156 \\
(0.203) \\
\end{array}$ & 0.247 & 0.267 & 0.288 \\
\hline & Average & 0.246 & 0.268 & 0.300 \\
\hline
\end{tabular}

\subsection{Carbon fiber /vinyl ester composites}

The thermal conductivity values of carbon fiber/vinyl ester composite materials in longitudinal, transverse and through-the-thickness directions are listed in Table 5.6. Note that carbon fibers are all unidirectional.

The following observations are made from the test results of carbon fiber/vinyl ester composite material: 1) the thermal conductivities of carbon composites are the highest along the fiber direction, medium in the transverse direction and lowest in through-the- thickness direction; 2) carbon composites have significantly different thermal conductivity values in three directions - strongly anisotropic. This is distinctively different from E-glass composite materials for which thermal conductivities in three directions are close - almost isotropic; 3) thermal conductivity of carbon composites through the thickness direction is close to that of neat resin, indicating that thermal property of the resin plays a major role in this direction; 4) Carbon composites result in lower thermal conductivity values in through-the-thickness direction than glass fiber 
composite. This observation is in accordance with the results published in the literature (Gowayed, 1994); and 5) As shown in Table 5.6, through-the-thickness thermal conductivity of carbon/vinyl ester composite block is consistent with that of carbon/ vinyl ester composite sheet.

Carbon fiber is orthotropic in nature and the conductivity of the carbon fiber along the axis would be higher than in other directions because of the basal plane formation along the axis. These basal planes are closely packed in the order of angstrom units, which helps in transferring heat quickly and by virtue of its property carbon fibers contracts upon heat due to negative expansion coefficient further reducing the distance between the basal planes. Thus thermal conductivity increased linearly in longitudinal direction in the measured temperature range of $60-100^{\circ} \mathrm{C}$. In transverse direction, conductivity would be much lower than that of in longitudinal direction due to lack of basal planes. Moreover, carbon sheets would be sized to have good compatibility with the resin, and this sizing causes an insulating layer and thus hinders heat flow in case of through the thickness direction. This glossy sizing over the carbon tow might be the reason for lower conductivity of carbon composite in through the thickness direction than that of a glass fiber composite.

To test the effect of fiber volume fraction of a composite on thermal conductivity, another carbon/vinyl ester block was made with higher fiber compactness and tested. The results are also included in Table 5.6. During the sample preparation, sample for "heat flow in transverse direction" in Carbon block II was damaged a little at the edges and cracks were formed around the periphery. These issues lowered the conductivity of the sample in transverse direction. The fiber volume fraction of second block (75\%) was more than the first block $(60 \%)$ and hence, the thermal conductivity along zero (along the fiber) direction was nearly double and the thermal conductivity through-the-thickness direction increased by $13 \%$. The results are compared graphically in Figure 5.5.

The fiber volume fractions of these samples were approximated using SEM and areal method of finding fiber volume fraction. The fiber volume fractions for the first and second block were found through SEM to be around $60 \%, 75 \%$ respectively. The pictures representing number of layers and fiber alignment for each sample are shown in Figure 3.3 . 
Table 5.6 Thermal conductivities of carbon fiber/vinyl ester composite blocks I, II

\begin{tabular}{|c|c|c|c|c|}
\hline \multirow[b]{2}{*}{$\begin{array}{l}\text { Heat flow } \\
\text { direction }\end{array}$} & \multirow[b]{2}{*}{$\begin{array}{c}\text { Thickness } \\
\text { mm } \\
\text { (inch) }\end{array}$} & \multicolumn{3}{|c|}{ Thermal conductivity, $\mathrm{W} / \mathrm{m} \mathrm{K}$} \\
\hline & & $\begin{array}{c}\text { Segment } 1 \\
\text { at } 140^{\circ} \mathrm{F} \\
\left(60^{\circ} \mathrm{C}\right)\end{array}$ & $\begin{array}{c}\text { Segment } 2 \\
\text { at } 140^{\circ} \mathrm{F} \\
\left(80^{\circ} \mathrm{C}\right)\end{array}$ & $\begin{array}{c}\text { Segment } 3 \\
\text { at } 212^{0} \mathrm{~F} \\
\left(100^{\circ} \mathrm{C}\right)\end{array}$ \\
\hline Thickness & $\begin{array}{c}1.816 \\
(0.0715)\end{array}$ & 0.291 & 0.306 & 0.323 \\
\hline \multicolumn{5}{|c|}{ Carbon/Vinyl ester Composite Block I } \\
\hline \multirow{3}{*}{ Thickness } & $\begin{array}{c}6.934 \\
(0.273) \\
\end{array}$ & 0.232 & 0.270 & 0.289 \\
\hline & $\begin{array}{c}6.934 \\
(0.273) \\
\end{array}$ & 0.245 & 0.262 & 0.282 \\
\hline & Average & 0.239 & 0.266 & 0.286 \\
\hline \multirow{3}{*}{$\begin{array}{l}\text { Transverse } \\
(\perp 0 \text { fiber })\end{array}$} & $\begin{array}{c}6.612 \\
(0.2603)\end{array}$ & 0.471 & 0.506 & 0.544 \\
\hline & $\begin{array}{c}5.639 \\
(0.222)\end{array}$ & 0.457 & 0.501 & 0.542 \\
\hline & Average & 0.464 & 0.504 & 0.543 \\
\hline \multirow{3}{*}{$\begin{array}{l}\text { Longitudinal } \\
\text { (// } 0 \text { fiber) }\end{array}$} & $\begin{array}{c}7.163 \\
(0.282)\end{array}$ & 0.966 & 1.205 & 1.379 \\
\hline & $\begin{array}{c}6.764 \\
(0.2663) \\
\end{array}$ & 0.785 & 0.965 & 1.231 \\
\hline & Average & 0.876 & 1.085 & 1.305 \\
\hline \multicolumn{5}{|c|}{ Carbon/Vinyl ester Composite Block II } \\
\hline \multirow{3}{*}{ Thickness } & $\begin{array}{l}19.964 \\
(0.786)\end{array}$ & 0.296 & 0.297 & 0.312 \\
\hline & $\begin{array}{c}20.129 \\
(0.7925)\end{array}$ & 0.313 & 0.323 & 0.334 \\
\hline & Average & 0.305 & 0.310 & 0.323 \\
\hline $\begin{array}{l}\text { Transverse } \\
\text { ( } \perp 0 \text { fiber) }\end{array}$ & $\begin{array}{l}20.269 \\
(0.798)\end{array}$ & 0.426 & 0.442 & 0.453 \\
\hline \multirow{3}{*}{$\begin{array}{l}\text { Longitudinal } \\
\text { (// } 0 \text { fiber) }\end{array}$} & $\begin{array}{c}20.073 \\
(0.7903)\end{array}$ & 1.904 & 2.146 & 2.603 \\
\hline & $\begin{array}{c}20.25 \\
(0.7972)\end{array}$ & 1.367 & 1.643 & 2.211 \\
\hline & Average & 1.636 & 1.895 & 2.407 \\
\hline
\end{tabular}

*Sample damaged a little at the edges and cracks were formed around the periphery during sample preparation 


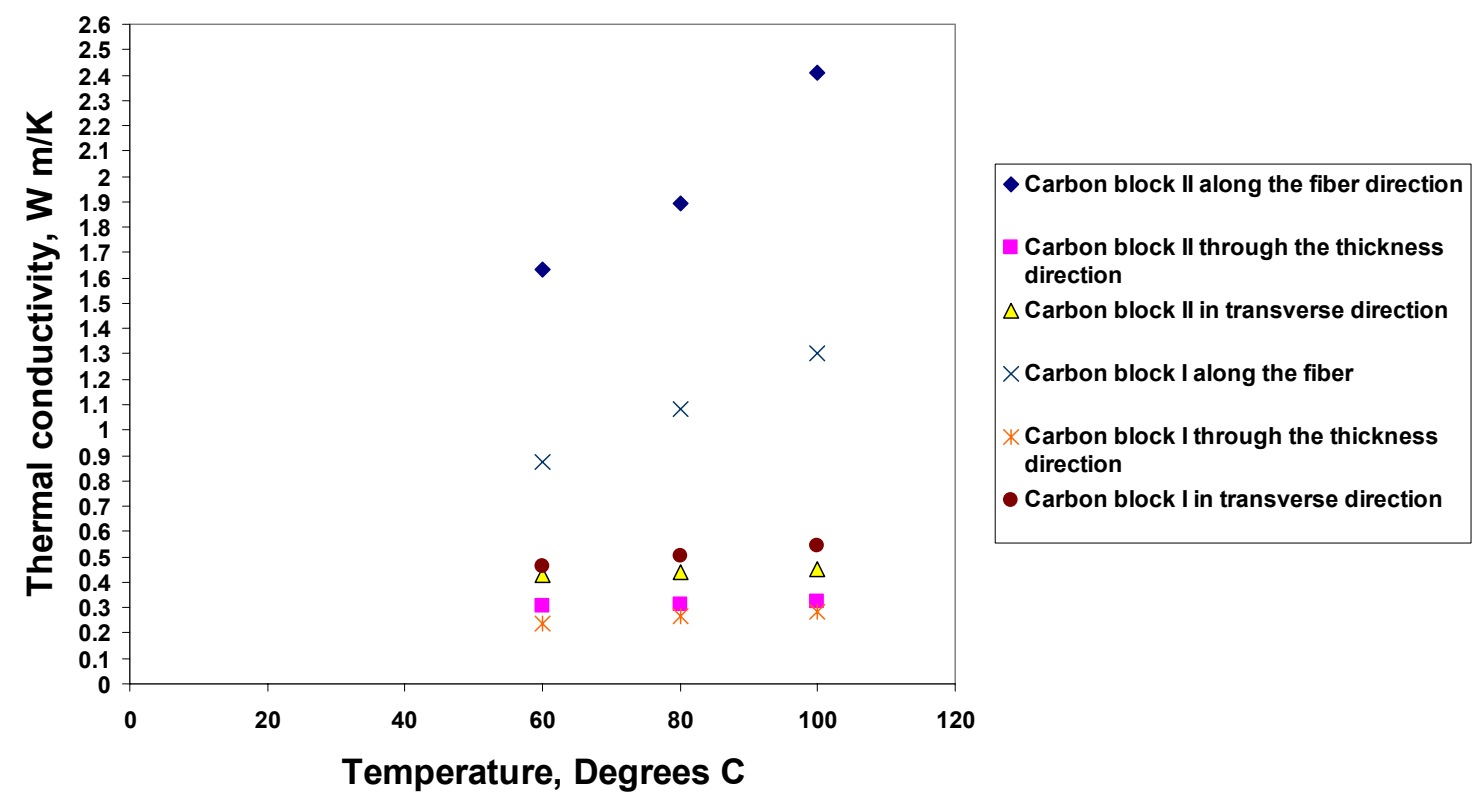

Figure 5.5 Thermal conductivity variations for Carbon/Vinyl ester composites

\subsection{Prodeck 4 and Prodeck 8 bridge deck samples}

The thermal conductivities of FRP bridge deck samples are listed in Tables 5.7 5.11. 4-inch deep FRP bridge deck material shows slightly lower thermal conductivity than that of an 8-inch deep FRP bridge deck (as seen in Table 5.6 in the thickness direction). It is observed that the thermal conductivity of the bridge deck samples varied from $0.34 \mathrm{~W} / \mathrm{m} \mathrm{K}$ to $0.42 \mathrm{~W} / \mathrm{m} \mathrm{K}$. As these samples were fetched from the bridge deck samples across the thickness from different locations, there would be a variation in fiber volume fraction, fiber orientation, and fiber architecture. This explains the variation of thermal conductivities at different sections of the bridge deck. The overall thermal conductivity of the bridge deck could be calculated using these values. Considering an 8 inch bridge deck composite, it has a thermal conductivity value of $0.35 \pm 0.05 \mathrm{~W} / \mathrm{m} \mathrm{K}$ in through-the-thickness and longitudinal directions. 
Table 5.7 Thermal conductivity of FRP bridge deck samples in three directions

\begin{tabular}{|l|c|c|c|c|c|}
\hline \multirow{2}{*}{ Sample } & \multirow{2}{*}{$\begin{array}{c}\text { Thickness } \\
\mathrm{mm} \\
\text { (inch) }\end{array}$} & Heat flow & \multicolumn{3}{|c|}{ Thermal conductivity, W/m K } \\
\cline { 4 - 6 } & $\begin{array}{c}\text { direction } \\
\text { 8" deck with CSM }\end{array}$ & $\begin{array}{c}\text { Segment } 1 \\
\text { at } 140^{\circ} \mathrm{F} \\
\left(60^{\circ} \mathrm{C}\right)\end{array}$ & $\begin{array}{c}\text { Segment } 2 \\
\text { at } 140^{0} \mathrm{~F} \\
\left(80^{\circ} \mathrm{C}\right)\end{array}$ & $\begin{array}{c}\text { Segment } 3 \\
\text { at } 212^{0} \mathrm{~F} \\
\left(100^{\circ} \mathrm{C}\right)\end{array}$ \\
\hline $\begin{array}{l}4.6228 \\
\text { removed }\end{array}$ & $\begin{array}{c}4.15974 \\
(0.183)\end{array}$ & $\begin{array}{c}\text { Thickness } \\
\text { (// 90 fiber) }\end{array}$ & 0.375 & 0.388 & 0.401 \\
\cline { 2 - 6 } & $\begin{array}{c}4.9784 \\
(0.190)\end{array}$ & $\begin{array}{c}\text { Longitudinal } \\
\text { (// 0 fiber) }\end{array}$ & 0.289 & 0.306 & 0.331 \\
\hline 4" deck with CSM & $\begin{array}{c}5.1816 \\
(0.190)\end{array}$ & Thickness & 0.300 & 0.331 & 0.365 \\
\hline
\end{tabular}

Each reported value is an average of three or four runs of measurements; it is shown that the longitudinal thermal conductivity is slightly lower than that along the transverse direction. These results are consistent with the results obtained from section 5.7. This might be due to the presence of fibers in different directions in longitudinal direction instead of having unidirectional fibers. The reason for higher conductivity across the thickness and lower conductivity along the fiber direction in the case of Eglass/Vinyl ester has to be further researched. However, the difference in thermal conductivity value among three directions is not significant. Although there is a variation in conductivity value for different directions, the thermal conductivity of E-glass/vinyl ester composites shows a weak dependence on the fiber orientation. This observation is attributed to the following reasons: 1) glass fiber has nearly the same thermal conductivity along the transverse direction as that of longitudinal direction; 2) glass fiber's thermal conductivity is only slightly higher than that of vinyl ester; 3) pultruded structural parts have a high fiber volume content; and 4) pultruded structural parts have a balanced fiber content distribution both along the transverse and longitudinal directions. 
Table 5.8 Thermal conductivity values of 4-inch deck web section samples

\begin{tabular}{|l|c|c|c|c|c|}
\hline & \multirow{2}{*}{ Sample } & \multirow{2}{*}{$\begin{array}{c}\text { Thickness } \\
\mathrm{mm} \\
(\mathrm{inch})\end{array}$} & $\begin{array}{c}\text { Fiber } \\
\text { volume } \\
\text { fraction, } \\
\%\end{array}$ & \multicolumn{3}{|c|}{\begin{tabular}{c} 
Thermal conductivity, W/m K \\
\cline { 4 - 6 }
\end{tabular}} & $\begin{array}{c}\text { Segment } 140^{\circ} \mathrm{F} \\
\left(60^{\circ} \mathrm{C}\right)\end{array}$ & $\begin{array}{c}\text { Segment } 2 \\
\text { at } 140^{\circ} \mathrm{F} \\
\left(80^{\circ} \mathrm{C}\right)\end{array}$ & $\begin{array}{c}\text { Segment } 3 \\
\text { at } 212^{0} \mathrm{~F} \\
\left(100^{\circ} \mathrm{C}\right)\end{array}$ \\
\hline $\begin{array}{l}\text { Bottom } \\
\text { Section }\end{array}$ & $\begin{array}{c}4.68 \\
(0.1842)\end{array}$ & 51.83 & 0.305 & 0.323 & 0.336 \\
\hline $\begin{array}{l}\text { Middle } \\
\text { Section }\end{array}$ & $\begin{array}{c}4.997 \\
(0.1967)\end{array}$ & 53.67 & 0.322 & 0.351 & 0.38 \\
\hline $\begin{array}{l}\text { Top } \\
\text { Section }\end{array}$ & $\begin{array}{c}4.743 \\
(0.1867)\end{array}$ & 46.68 & 0.264 & 0.313 & 0.382 \\
\hline
\end{tabular}

Table 5.9 Thermal conductivity values of 4 -inch deck flange section samples

\begin{tabular}{|c|c|c|c|c|c|}
\hline \multirow[b]{2}{*}{ Sample } & \multirow{2}{*}{$\begin{array}{c}\text { Thickness } \\
\text { mm } \\
\text { (inch) }\end{array}$} & \multirow{2}{*}{$\begin{array}{c}\text { Fiber } \\
\text { volume } \\
\text { fraction, } \\
\%\end{array}$} & \multicolumn{3}{|c|}{ Thermal conductivity, W/m K } \\
\hline & & & $\begin{array}{c}\text { Segment } 1 \\
\text { at } 140^{0} \mathrm{~F} \\
\left(60^{\circ} \mathrm{C}\right)\end{array}$ & $\begin{array}{c}\text { Segment } 2 \\
\text { at } 140^{\circ} \mathrm{F} \\
\left(80^{\circ} \mathrm{C}\right)\end{array}$ & $\begin{array}{c}\text { Segment } 3 \\
\text { at } 212^{0} \mathrm{~F} \\
\left(100^{\circ} \mathrm{C}\right)\end{array}$ \\
\hline $\begin{array}{l}\text { Bottom } \\
\text { Section }\end{array}$ & $\begin{array}{c}5.194 \\
(0.2045)\end{array}$ & 60.66 & 0.227 & 0.287 & 0.343 \\
\hline $\begin{array}{l}\text { Middle } \\
\text { Section * }\end{array}$ & $\begin{array}{l}5.08 \\
(0.2)\end{array}$ & 53.82 & 0.175 & 0.19 & 0.208 \\
\hline $\begin{array}{l}\text { Top } \\
\text { Section }\end{array}$ & $\begin{array}{c}4.896 \\
(0.1927)\end{array}$ & 58.33 & 0.32 & 0.334 & 0.35 \\
\hline
\end{tabular}

*indicates a problem while testing and to be tested again with a new sample 
Table 5.10 Thermal conductivity values of 8-inch deck web section samples

\begin{tabular}{|c|c|c|c|c|c|}
\hline \multirow[b]{2}{*}{ Sample } & \multirow{2}{*}{$\begin{array}{l}\text { Thickness } \\
\text { mm } \\
\text { (inch) }\end{array}$} & \multirow{2}{*}{$\begin{array}{c}\text { Fiber } \\
\text { volume } \\
\text { fraction, } \\
\quad \%\end{array}$} & \multicolumn{3}{|c|}{ Thermal conductivity, W/m K } \\
\hline & & & $\begin{array}{c}\text { Segment } 1 \\
\text { at } 140^{\circ} \mathrm{F} \\
\left(60^{\circ} \mathrm{C}\right)\end{array}$ & $\begin{array}{c}\text { Segment } 2 \\
\text { at } 140^{\circ} \mathrm{F} \\
\left(80^{\circ} \mathrm{C}\right)\end{array}$ & $\begin{array}{c}\text { Segment } 3 \\
\text { at } 212^{0} \mathrm{~F} \\
\left(100^{\circ} \mathrm{C}\right)\end{array}$ \\
\hline $\begin{array}{l}\text { Bottom } \\
\text { Section }\end{array}$ & $\begin{array}{c}4.534 \\
(0.1784)\end{array}$ & 53.46 & 0.304 & 0.340 & 0.36 \\
\hline $\begin{array}{l}\text { Middle } \\
\text { Section }\end{array}$ & $\begin{array}{c}4.909 \\
(0.1932)\end{array}$ & 54.20 & 0.395 & 0.417 & 0.427 \\
\hline $\begin{array}{l}\text { Top } \\
\text { Section }\end{array}$ & $\begin{array}{c}4.813 \\
(0.1895)\end{array}$ & 59.08 & 0.312 & 0.348 & 0.381 \\
\hline
\end{tabular}

Table 5.11 Thermal conductivity values of 8-inch deck flange section samples

\begin{tabular}{|c|c|c|c|c|c|}
\hline \multirow[b]{2}{*}{ Sample } & \multirow{2}{*}{$\begin{array}{c}\text { Thickness } \\
\text { mm } \\
\text { (inch) }\end{array}$} & \multirow{2}{*}{$\begin{array}{c}\text { Fiber } \\
\text { volume } \\
\text { fraction, } \\
\%\end{array}$} & \multicolumn{3}{|c|}{ Thermal conductivity, W/m K } \\
\hline & & & $\begin{array}{c}\text { Segment } 1 \\
\text { at } 140^{\circ} \mathrm{F} \\
\left(60^{\circ} \mathrm{C}\right)\end{array}$ & $\begin{array}{c}\text { Segment } 2 \\
\text { at } 140^{\circ} \mathrm{F} \\
\left(80^{\circ} \mathrm{C}\right)\end{array}$ & $\begin{array}{c}\text { Segment } 3 \\
\text { at } 212^{0} \mathrm{~F} \\
\left(100^{\circ} \mathrm{C}\right)\end{array}$ \\
\hline $\begin{array}{l}\text { Bottom } \\
\text { Section }\end{array}$ & $\begin{array}{c}5.023 \\
(0.1978)\end{array}$ & 57.27 & 0.335 & 0.368 & 0.396 \\
\hline $\begin{array}{l}\text { Middle } \\
\text { Section }\end{array}$ & $\begin{array}{c}4.823 \\
(0.1845)\end{array}$ & 61.23 & 0.335 & 0.368 & 0.391 \\
\hline \begin{tabular}{|l|} 
Top \\
Section \\
\end{tabular} & $\begin{array}{c}5.093 \\
(0.2005) \\
\end{array}$ & 55.36 & 0.376 & 0.395 & 0.421 \\
\hline
\end{tabular}




\section{CHAPTER 6}

\section{VALIDATION OF MODEL PREDICTIONS}

\subsection{Introduction}

Analytical or numerical models help to predict the properties of a material without conducting any experiments. However, these models have to be extensively validated with experimental data before adopting them in practice on a large scale. Most of the literature on composite materials (anisotropic) dealt with mechanical properties and very few models were developed to predict thermal conductive properties in different directions. Experimentally determined mechanical properties can be verified with the previously published analytical models; however limited models on thermal conductivity are available for cursory verification. Most of the literature predicts through-the-thickness effective thermal conductivity, while thermal conductivity along the fiber direction in a composite can be predicted using rule of mixtures. In this chapter, experimental results obtained for the E-glass/vinyl ester samples are validated for through-the-thickness effective thermal conductivity and longitudinal effective thermal conductivity.

\subsection{Analytical models and validation}

Thermal conductivities through-the-thickness and longitudinal directions are verified using the theoretical models described in Chapter 2. The equations from these models are tabulated again in Table 6.1 for a quick reference. In this study, thermal conductivity considered for validation purpose is the value obtained at a temperature of $60^{\circ} \mathrm{C}$. The thermal conductivity of the vinyl ester matrix was experimentally determined as $0.213 \mathrm{~W} / \mathrm{m} \mathrm{K}$ and this value is repetitive and also in accordance with the data provided by the manufacturers' data sheet (www.ashland.com). The thermal conductivity of Eglass fiber was given as $0.5 \mathrm{~W} / \mathrm{m} \mathrm{K}$ and these data were provided by the manufacturer (www.fgi.com). As the thermal conductivity value of the FORCA tow sheets used in making Carbon/Vinyl ester block was not available, an approximate thermal conductivity value for PAN based Carbon fiber was considered from the literature (Gowayed, 1995) and the data from AMOCO Performance Products. Thermal conductivity along the axis of the carbon (PAN) fiber was considered as $8 \mathrm{~W} / \mathrm{m}-\mathrm{K}$. However, the thermal 
conductivity in transverse direction will be 10 to 15 times less than that of the conductivity value in along the fiber direction (Gowayed, 1995 and www.cytec.com). In the present case thermal conductivity in transverse direction was taken as 15 times lower than the conductivity in axial direction, which is $0.533 \mathrm{~W} / \mathrm{m} \mathrm{K}$. These assumed values are not for validation of the experimental data obtained in this study; but to verify how the theoretical models perform at higher fiber volume fractions like $60 \%$ or $75 \%$ as in case of carbon/vinyl ester composite and at higher thermal conductivities like $8 \mathrm{~W} / \mathrm{m} \mathrm{K}$.

Table 6.1 Theoretical models for transverse effective thermal conductivity

\begin{tabular}{|c|c|c|c|}
\hline S.No & Author & Model & Notes \\
\hline 6.1 & $\begin{array}{c}\text { Springer and } \\
\text { Tsai }\end{array}$ & $\begin{array}{c}\mathrm{K}_{22}=\mathrm{K}_{\mathrm{m}}\left[1-2 \sqrt{\frac{V_{f}}{\pi}}\right]+\frac{1}{B}\left(\pi-\frac{4}{\sqrt{1-\left(\frac{B^{2} V_{f}}{\pi}\right)}} \tan ^{-1}\left(\frac{\sqrt{1-\frac{B^{2} V_{f}}{\pi}}}{1+\sqrt{\frac{B^{2} V_{f}}{\pi}}},\right.\right. \\
\text { where } \mathrm{B} \equiv 2\left(\frac{K_{m}}{K_{f}}-1\right)\end{array}$ & $\begin{array}{l}\text { - Assumes matrix and fiber as } \\
\text { parallel and series as in } \\
\text { electrical circuits. } \\
\text { - Assumes fiber patterns as } \\
\text { square, cylindrical and } \\
\text { elliptical shapes }\end{array}$ \\
\hline 6.2 & $\begin{array}{c}\text { Hashin } \\
\text { (Cylindrical } \\
\text { assemblage model) }\end{array}$ & $K_{e}=K_{f}\left[\frac{K_{f} V_{f}+K_{m}\left(1+V_{m}\right)}{K_{f}\left(1+V_{m}\right)+K_{m} V_{f}}\right]$ & $\begin{array}{l}\text { - Gives upper and lower } \\
\text { bound for transverse } \\
\text { conductivity } \\
\text { - Considers phase geometry }\end{array}$ \\
\hline 6.3 & Caruso & $\mathrm{K}_{\mathrm{T}}=1-\sqrt{V_{f}} K_{m}+\frac{\sqrt{\mathrm{V}_{\mathrm{f}}} * \mathrm{~K}_{\mathrm{m}}}{1-\sqrt{\mathrm{V}_{\mathrm{f}}}\left(1-\frac{\mathrm{K}_{\mathrm{m}}}{\mathrm{K}_{\mathrm{fl}}}\right)}$ & $\begin{array}{l}\text { - Considered square lattice } \\
\text { - Unidirectional fibers }\end{array}$ \\
\hline 6.4 & Halpin Tsai & $k_{2}=k_{m}\left[\frac{1+\xi \eta V_{f}}{1-\eta V_{f}}\right] ; \eta=\frac{\left(\begin{array}{c}k_{f} / k_{m} \\
\left(k_{f} / k_{m}\right)+\xi\end{array}\right)-1}{(k)}$ & $\begin{array}{l}\text { - Widely used thermal } \\
\text { transport formula for } \\
\text { transverse conductivity } \\
\text { - Useful for different shapes of } \\
\text { filaments, } \xi=1 \text { for circular } \\
\text { fibers }\end{array}$ \\
\hline 6.5 & $\begin{array}{l}\text { Inverse rule of } \\
\text { mixtures }\end{array}$ & $\frac{1}{K_{T}}=\frac{V_{f}}{K_{f}}+\frac{V_{m}}{K_{m}}$ & $\begin{array}{l}\text { - Derived from rule of } \\
\text { mixtures to calculate for } \\
\text { transverse } \\
\text { conductivity } \\
\text { - Does not consider voids, } \\
\text { fabric overlap }\end{array}$ \\
\hline
\end{tabular}


The samples considered for validation are E-glass vinyl ester block, Carbon/Vinyl ester blocks I and II as described in Chapter 5. The details about the samples are given in Table 6.2. $\mathrm{K}_{\mathrm{ff}}, \mathrm{K}_{\mathrm{ft}}, \mathrm{K}_{\mathrm{m}}$ represents thermal conductivity of fiber along the axis of the fiber, transverse to the fiber and conductivity of the matrix respectively. $V_{f}$ and $V_{m}$ represent the fiber and matrix volume fractions respectively.

Table 6.2 Parameters of the samples verified using theoretical methods

\begin{tabular}{|c|c|c|c|c|c|}
\hline Sample & $\begin{array}{c}\mathrm{K}_{\mathrm{fl}}, \\
\mathrm{W} / \mathrm{m} \mathrm{K}\end{array}$ & $\begin{array}{c}\mathrm{K}_{\mathrm{ft}} \\
\mathrm{W} / \mathrm{m} \mathrm{K}\end{array}$ & $\begin{array}{c}\mathrm{K}_{\mathrm{m}} \\
\mathrm{W} / \mathrm{m} \mathrm{K}\end{array}$ & $\mathrm{V}_{\mathrm{f}}, \%$ & $\mathrm{~V}_{\mathrm{m}}, \%$ \\
\hline E glass/Vinyl ester & 0.5 & 0.5 & 0.213 & 53.55 & 46.45 \\
\hline Carbon/Vinyl ester I & 8 & 0.533 & 0.213 & 60 & 40 \\
\hline Carbon/Vinyl ester II & 8 & 0.533 & 0.213 & 75 & 25 \\
\hline
\end{tabular}


Table 6.3 Comparison of experimental and theoretical values in (through the thickness effective thermal conductivity) for $E$ glass/Vinyl ester sample and

\section{Carbon/Vinyl ester samples}

\begin{tabular}{|l|c|c|c|}
\hline \multicolumn{1}{|c|}{ Method/Model } & $\begin{array}{c}\text { E glass/Vinyl } \\
\text { ester, W/m k }\end{array}$ & $\begin{array}{c}\text { Carbon/Vinylester I, } \\
\mathrm{W} / \mathrm{m} \mathrm{k}\end{array}$ & $\begin{array}{c}\text { Carbon/Vinylester II, } \\
\mathrm{W} / \mathrm{m} \mathrm{k}\end{array}$ \\
\hline Experimental & 0.322 & 0.239 & 0.304 \\
\hline Springer Tsai & 0.307 & 0.354 & 0.410 \\
\hline $\begin{array}{l}\text { Cylindrical } \\
\text { assemblage model, } \\
\text { Hashin }\end{array}$ & 0.330 & 0.360 & 0.415 \\
\hline Caruso model & 0.326 & 0.356 & 0.412 \\
\hline Halpin Tsai & 0.330 & 0.360 & 0.415 \\
\hline $\begin{array}{l}\text { Inverse rule of } \\
\text { mixture }\end{array}$ & 0.307 & 0.332 & 0.388 \\
\hline
\end{tabular}

Note: The above data for Carbon composite is used for comparison purpose between models but not between models and experimental results as the technical data for Carbon fiber is not available.

The experimental results for longitudinal effective thermal conductivity were verified using rule of mixtures. According to the rule of mixtures (ROM), the overall thermal conductivity of a composite can be given by Equation 6.6

$$
K_{1}=K_{f} V_{f}+K_{m} V_{m}
$$

Where $K_{1}$ is the overall longitudinal thermal conductivity of the composite, $K_{f}, K_{m}$ are the individual thermal conductivities of the fiber and matrix respectively and $V_{f}, V_{m}$ are the fiber volume fraction and matrix volume fraction of the composite. Comparison between experimental and theoretical values are shown in Table 6.4 
Table 6.4 Comparison of experimental and theoretical models for $\mathbf{E}$ glass/Vinyl ester sample and Carbon/Vinyl ester samples for longitudinal effective thermal conductivity using rule of mixtures

\begin{tabular}{|c|c|c|c|c|c|c|}
\hline Sample & $\begin{array}{c}\mathrm{K}_{\mathrm{fl}}, \\
\mathrm{W} / \mathrm{m} \mathrm{K}\end{array}$ & $\begin{array}{c}\mathrm{K}_{\mathrm{m}} \\
\mathrm{W} / \mathrm{m} \mathrm{K}\end{array}$ & $\mathrm{V}_{\mathrm{f}}, \%$ & $\mathrm{~V}_{\mathrm{m}}, \%$ & $\begin{array}{c}\text { Experimental } \\
\mathrm{W} / \mathrm{m} \mathrm{K}\end{array}$ & $\begin{array}{c}\text { Theoretical } \\
\mathrm{W} / \mathrm{m} \mathrm{K}\end{array}$ \\
\hline $\begin{array}{c}\text { E glass/ } \\
\text { Vinyl ester }\end{array}$ & 0.5 & 0.213 & 53.55 & 46.45 & 0.246 & 0.367 \\
\hline $\begin{array}{c}\text { Carbon/ } \\
\text { Vinyl ester I }\end{array}$ & 8 & 0.213 & 60 & 40 & 0.876 & 4.885 \\
\hline $\begin{array}{c}\text { Carbon/ } \\
\text { Vinyl ester II }\end{array}$ & 8 & 0.213 & 75 & 25 & 1.636 & 5.650 \\
\hline
\end{tabular}

\subsection{Discussion}

The experimental results obtained from E glass/Vinyl ester sample in through-thethickness direction are in good agreement $(\sim 10 \%)$ with the theoretical models. Along longitudinal direction, rule of mixtures was applied and that value is slightly more than the experimental value. In general, rules of mixture over estimate the experimental value and inverse rule of mixture under estimates (Barbero, 1998). This fact was proven with this comparison.

In case of carbon composite, the assumed conductivity values of fiber in throughthe-thickness direction shows that the theoretical models are presenting reasonably close values even for high volume fraction and high thermal conductivity (values obtained from theoretical models were not compared with experimental data). The comparison between experimental and theoretical values in both through-the-thickness and in longitudinal direction reveals that the assumed value for thermal conductivity of carbon fiber along the axis of the fiber and transverse to the fiber are not appropriate. 


\section{CHAPTER 7}

\section{CONCLUSIONS AND RECOMMENDATIONS}

\subsection{Introduction}

In this chapter the conclusions are drawn from data obtained from literature and our experimental results. Validation of experimental results with available models in literature are being discussed along with the recommendations for future work

\subsection{Conclusions}

Chapter 2

1. In case of thermal characterization of composite materials, few theoretical and limited experimental methods are available.

2. Some theoretical models available are of no good use for the validation of experimental results, as they require various properties of fibers and matrix, which are difficult to acquire for practical purpose.

3. Most of the models do not consider for thermal resistance, interaction between fiber and matrix and fiber orientation.

\section{Chapter 5}

4. From section 5.2, thermal conductivity values of three different matrices Polyester, Vinyl ester and Epoxy were given as 0.209, 0.213, and 0.229 respectively thus showing nearly the same thermal conductivity values.

5. From section 5.2, addition of $10 \mathrm{wt} \%$ and $12.5 \mathrm{wt} \%$ of graphite additive in neat vinyl ester resin increased the conductivity by $88 \%$ and $170 \%$ respectively. Addition of $0.15 \mathrm{wt} \%$ and $0.3 \mathrm{wt} \%$ of chopped carbon fibers in neat vinyl ester resin resulted in increase of conductivity values by $12.5 \%$ and $19 \%$ respectively. It was also observed that the finer particulates are better (by $\sim 19 \%$ ) in increasing the conductivity than the coarser particulates in an additive at the same concentration. 
6. From section 5.7, in case of bi-axial E-glass/Vinyl ester composite, the conductivity is nearly $18 \%$ more in through-the-thickness direction than in transverse and longitudinal directions.

7. From section 5.8, thermal conductivity along longitudinal direction in case of Carbon/Vinyl ester composite is almost twice the conductivity in transverse and four times greater than through-the-thickness direction. Further more, increase in fiber volume fraction from $60 \%$ to $75 \%$ almost doubled the conductivity (from $1.035 \mathrm{~W} / \mathrm{m} \mathrm{K}-2.407 \mathrm{~W} / \mathrm{m} \mathrm{K}$ ) along longitudinal direction and showed significant increase of conductivity in through-the-thickness direction.

8. From section 5.9, in case of bridge deck samples, Prodeck 4 has lower conductivity value $(0.3 \mathrm{~W} / \mathrm{m} \mathrm{K})$ when compared to Prodeck $8(0.375 \mathrm{~W} / \mathrm{m} \mathrm{K})$.

\section{Chapter 6}

9. From Tables 6.2 and 6.3, experimental results obtained from E-glass/Vinyl ester sample in longitudinal and through-the-thickness direction are in good agreement with the values obtained from theoretical models. In longitudinal direction, rules of mixture showed an upper bound value and in through-the-thickness direction inverse rule of mixture showed a lower bound experimental data.

\subsection{Recommendations for future work}

1. Determining three dimensional thermal conductivity behaviors of uni-directional glass fiber composites so that it clarifies the confusion caused by the results obtained from bi-axial glass fiber composites.

2. Testing the samples with wide range of volume fractions with adequate knowledge about conductivity value of fiber and matrix.

3. Establishing thermal conductivity for a wide range of temperature from room temperature to maximum service temperature.

4. Verification of effect of fiber orientation by testing composites with different orientations along with uni-directional and cross-ply composites. 
5. Control over manufacturing methods to reduce anomaly like fiber distortion, void content and to attain required fiber volume fractions.

6. Usage of precision tools to maintain required surface finish of the sample to acquire more accurate results. 


\section{BIBLIOGRAPHY}

Alcaraz, D., J.A. Moreno and F.Alhama (2003) Thermal conductivity in continuous metal matrix composites with random distributions, Material Science Forum, Vols. 426-432, 2169-2174

ANTER Corporation technical notes (2003) http://www.anter.com/tech_notes.htm

ASM Handbook, Volume 21, Composites, 2001

Barbero, Ever J. (1998) Introduction to Composite Materials Design, Taylor \& Francis

Behrens, Ernest (1968) Thermal conductivities of composite materials, J. Composite Materials, Vol.2, No.1, 2-17

Callister, D Williams Jr. (1990) Material Science and Engineering An Introduction, John Wiley and Sons, Inc

Caruso, J. and Cristos C. Chamis (1986) Assessment of simplified composite micromechanics using three dimensional finite element analysis, J. Composites Technology and Research, Vol.8, No.3, 77-83

Colton, Jonathan (2005) Natural fiber-polyolefin composites (Presentation) http://www.me.gatech.edu/jonathan.colton/me4793/natfiber.pdf

Donald, J. J and John. W. Walkinshaw (1988) Flash pulse measurement for off axis thermal conductivity of carbon composite material, American Chemical Society.

Gowayed, Yasser and Jhy-Cherng Hwang (1995) Thermal conductivity of composite materials made from plain weaves and 3-D weaves, Composites Engineering, Vol. 5(9), 1177-1186

Han, L.S. and A. A. Cosner (1981) Effective thermal conductivities of fibrous composites, Journal of Heat Transfer, Vol.103, 387-392

Hashin, Z. (1979) Analysis of properties of fiber composites with anisotropic constituents. ASME Applied Mechanics Vol. 46, 543-550

Hiroshi, Hatta and Minoru Taya (1985). Effective thermal conductivities of a misoriented short fiber composite. Journal of Applied Physics, Vol. 58 (7), 2478-2486

James W.B, Wostenholm H.G, Keen S.G and McIvor D S (1987), Prediction and Measurement of Thermal Conductivity of Composite Materials, Journal of Physics D, Vol. 20, 261-268 
Joshi, V.S., Drzal, T.L., Mohanty, K.A, and Arora, S (2004), Are Natural Fiber Composites Environmentally Superior to Glass Fiber Reinforced Composites?, Composites Part A, Vol 35, 371-376

Lim, T. C. (2002) Unified practical bounds for the thermal conductivity of composite materials, Materials Letters, 54, 152-157

Mirmira, Srinivas RangaRao (1999). Thermal conductivity of fibrous composites: experimental and analytical study. Ph D Dissertation, Texas A\&M, USA

Mottaram, J. T. and R. Taylor (1987). Thermal conductivity of fiber- phenolic resin composites, Part II: numerical evaluation. Composite Science and Technology, Vol.29, 211-232

Muralidhar, K. (1989) Equivalent conduction of a heterogeneous medium, International Journal of Heat Mass Transfer, Vol.33, No.8, 1759-1766

Parker, W.J., R.J. Jenkins, C.P. Butler, and G.L. Abbott (1961) A flash method of determining thermal diffusivity, heat capacity, and thermal conductivity, Journal of Applied Physics, 32 (9), 1679-1684

Rouison, David., Varejka, Milena and Picot, Jules (2002), Thermal Sensor to Monitor Mechanical Properties in Polymer/Fiber Composite Molding, The Canadian Journal of Chemical Engineering, Vol.80, 943-947

Springer, George S and Stephen W. Tsai (1967) Thermal conductivity of unidirectional materials, Journal of Composite Materials, Vol.1, 166-173

Zmeskal Oldrich, Buchnicek and Nezadal Matin (2003), Thermophysics proceedings 2003, 84-88 